\title{
Estudo do Concreto Asfáltico Estocável
}

\author{
Study of Cold Patch Asphalt Concrete
}

\author{
Isabela Silva de Carvalho ${ }^{1}$, Lilian Ribeiro de Rezende ${ }^{2}$, \\ João Paulo Souza Silva ${ }^{3}$, Douglas Andrez Tavares Rezende ${ }^{4}$
}

\begin{abstract}
${ }^{1}$ Mestre pelo Programa de Pós-graduação em Geotecnia, Estruturas e Construção Civil, Universidade Federal de Goiás, Av. Universitária, n. 1488, Leste Universitário, Goiânia, Goiás, Brasil.

${ }^{2}$ Escola de Engenharia Civil e Ambiental, Programa de Pós-graduação em Geotecnia, Estruturas e Construção Civil, Universidade Federal de Goiás, Av. Universitária, 1488, Leste Universitário, Goiânia, Goiás, Brasil.

${ }^{3}$ Faculdade de Ciência e Tecnologia, Programa de Pós-graduação em Geotecnia, Estruturas e Construção Civil, Universidade Federal de Goiás, Av. Universitária, 1488, Leste Universitário, Goiânia, Goiás, Brasil.

${ }^{4}$ Graduando, Curso de Engenharia Civil, Universidade Federal de Goiás, Av. Universitária, 1488, Leste Universitário, Goiânia, Goiás, Brasil.

e-mail: isabela.carvalho@discente.ufg.br,1rezende@ufg.br,jpss@ufg.br, douglasandrez@discente.ufg.br
\end{abstract}

\section{RESUMO}

Misturas asfálticas são os principais tipos de materiais que compõem as camadas de revestimentos asfálticos dos pavimentos brasileiros. Sabendo disso, este estudo teve por objetivo estudar misturas asfálticas, conhecidas como Concreto Asfáltico Estocável (CAE), que tem como diferencial a proposta de poder ser armazenada a granel ou ensacada e aplicada à frio. Foram realizadas as caracterizações físicas, volumétricas e mecânicas de três amostras de CAE de diferentes fabricantes com vistas a compreender sua composição e comportamento mecânico. Além disso, foram realizadas avaliações da granulometria utilizando as metodologias Bailey e Frações de Agregados Dominantes (FAD). Os resultados mostraram que as misturas de CAE não atenderam aos requisitos especificados em normas brasileiras e apresentaram resultados diferentes do esperado para um concreto asfáltico convencional, indicando que o mesmo não deve ser abordado como tal. Além disso, o CAE não atendeu aos parâmetros de trabalhabilidade e volumetria. Os resultados de viscosidade do ligante, do módulo dinâmico e do Flow Number indicaram que uma das amostras apresenta alta rigidez, fato que pode estar relacionado ao envelhecimento do ligante asfáltico e consequente enrijecimento da mistura. Por fim, verificou-se que o CAE apresenta envelhecimento durante a estocagem, o que não é adequado para misturas asfálticas. Logo, conclui-se que o mesmo, sem a adoção de critérios de controle de produção e aplicação, não é adequado para utilização como nova camada de revestimento, tendo seu uso limitado à serviços de manutenção como tapa-buraco.

Palavras-chave: Superpave. Deformação permanente. Avaliação mecânica. Método Bailey. FAD.

\section{ABSTRACT}

Asphalt mixtures are the main types of materials that make up the asphalt surface layers of Brazilian pavements. In this way, this study aimed to study asphalt mixtures, known as Stock Asphalt Concrete (CAE), which has as its differential the proposal to be stored in bulk or bagged and applied cold. The physical, volumetric and mechanical characterizations of three CAE samples from different manufacturers were performed to understand its composition and mechanical behavior. In addition, particle size evaluations were performed using Bailey and Dominant Aggregate Size Range (DASR) methodologies. The results showed that CAE mixtures did not meet the Brazilian standard requirements and presented different results than expected for a conventional asphalt concrete, indicating that it should not be approached as such. In addition, CAE did not meet the workability and volume parameters. The binder viscosity, dynamic modulus and Flow Number results indicated that one of the samples has high rigidity, which may be related to the aging of the asphalt binder and consequent stiffening of the mixture. Finally, it was found that CAE is aging during storage, which is not suitable for asphalt mixtures. Therefore, one concluded that CAE, without the adoption of pro- 
duction and application control criteria, cannot be used as a new surface course, and its application is limited only for maintenance works as blacktop.

Keywords: Superpave. Rutting. Mechanical evaluation. Bailey Method. DASR.

\section{INTRODUÇÃO}

O Concreto Asfáltico (CA) é uma mistura de agregados minerais com ligantes asfálticos, que, quando produzido e aplicado de forma correta, garante ao pavimento impermeabilidade, flexibilidade, estabilidade, durabilidade, resistência à derrapagem de veículos, resistência à fadiga e à deformação permanente, conforme apresentado por BERNUCCI et al. [1]. A estrutura do pavimento e o projeto de dosagem do revestimento visam garantir que todos os requisitos técnicos de qualidade sejam atendidos, sendo que a escolha dos materiais e a dosagem influenciam no comportamento mecânico do revestimento durante a ação do tráfego e do clima.

SEFIDMAZGI e BAHIA [2] mostraram em seu estudo que cada mistura asfáltica possui uma estrutura característica, sendo que esta pode variar de acordo com o tipo de agregado, ligante asfáltico, temperatura e grau de compactação. A estrutura interna do concreto asfáltico determina o suporte à deformação permanente, bem como o comportamento quanto à fadiga e à variação térmica. Alguns autores têm avaliado a influência de cada propriedade de misturas asfálticas em seu comportamento mecânico. ARAGÃO et al. [3] estudaram a influência da morfologia dos agregados minerais no comportamento de misturas asfálticas, concluindo que misturas com agregados rugosos e formato cúbico têm resistência a deformação permanente maior, quando comparadas com misturas com agregados lisos e arredondados, devido ao melhor intertravamento entre os grãos. ARCHILLA e DIAZ [4] consideraram a influência do grau de compactação, da performance do ligante e do teor de ligante na deformação permanente, sendo que dentre as três variáveis o volume de vazios é apresenta maior influência.

Com o desenvolvimento de métodos de dimensionamento mecanístico empíricos e da dosagem $\mathrm{Su}$ perpave, outras variáveis foram adicionadas na avaliação do comportamento mecânico de misturas asfálticas. Foram incluídos novos métodos de análise dos materiais, como o método Bailey e o método de Faixa de Agregados Dominantes (FAD), que permitem avaliar se a graduação da mistura é contínua e promove o empacotamento, no qual os grãos maiores estão interligados com os grãos menores preenchendo seus vazios.

KIM et al. [5] e FERREIRA et al. [6] validaram o método FAD para a seleção de granulometrias que resistem melhor à deformação permanente. KIM et al. [5] confirmaram que a porosidade FAD deve ser menor que 50\% para garantir bom intertravamento entre os agregados e bom desempenho mecânico da mistura. VAVRIK et al. [7] afirmaram que a seleção granulométrica pelo método Bailey garante maior intertravamento entre os agregados e, consequentemente, fornece maior resistência à deformação permanente. MENDES e MARQUES [8] também observaram que o uso do método Bailey possibilita a obtenção de maiores valores de Resistência à Tração (RT), Módulo de Resiliência (MR) e maior resistência à deformação permanente. Já FERREIRA et al. [6] verificaram que a porosidade FAD tem maior potencial como indicadora de resistência à deformação permanente e que o método Bailey não apresentou resultados coerentes.

Além dos métodos de avaliação da seleção granulométrica, tem-se também a inclusão dos parâmetros de densificação de misturas asfálticas na avaliação da trabalhabilidade e do comportamento mecânico. MAHMOUD e BAHIA [9] obtiveram que o parâmetro Flow Number (FN) tem uma boa correlação com o parâmetro Trafic Densification Index (TDI) medido durante a compactação. NASCIMENTO [10] também obteve boa correlação entre o parâmetro TDI e a deformação permanente para suas misturas estudadas. O autor ainda afirmou que para que as rodovias brasileiras tenham bom desempenho referente à deformação permanente, deve-se fixar os valores de CDI (Construction Desification Index) e TDI para os tráfegos médio e pesado. Já LEIVA e WEST [11] buscaram descobrir a causa de algumas misturas terem melhor densificação que outras em laboratório e verificaram que a granulometria, o tipo de agregado e o tamanho do agregado são as variáveis que mais influenciam na densificação de misturas produzidas no compactador giratório.

BARROSO [12] avaliaram o CDI e o TDI obtidos para um concreto asfáltico comumente utilizado em obras de pavimentação no estado de Goiás, composto de agregado do tipo micaxisto enquadrado na Faixa C do Departamento Nacional de Infraestrutura de Transportes (DNIT) e ligante asfáltico do tipo CAP 50/70. Os autores obtiveram que a mistura dosada pelo método Superpave apresenta baixos valores de CDI e TDI, indicando baixa resistência à deformação permanente, sendo que o FN obtido indica a limitação de utilização desse tipo de mistura apenas em vias de baixo e médio volume de tráfego.

O comportamento de misturas asfálticas vem sendo abordado por pesquisas nos últimos anos, assim como a utilização de novos materiais na produção de misturas asfálticas conforme discutido por ORESCOVIK et al. [13]. Esta busca por novos materiais visa trazer alternativas sustentáveis, econômicas e com efici- 
ência capaz de suprir as necessidades do tráfego rodoviário. Dentre as alternativas tem-se o uso de asfalto reciclado ou Reclaimed Asphalt Pavement (RAP), o pré-misturado a frio (PMF) e o asfalto modificado por polímero (AMP).

O Concreto Asfáltico Estocável (CAE) ou Asfalto Instantâneo é um material presente no mercado, mas ainda sem especificação técnica. O CAE é tido como um material com produção semelhante ao do CA com a utilização de um aditivo "retardador" de cura misturado ao ligante que, de acordo com os fabricantes, permite que o CAE seja aplicado a frio. Ainda segundo os fabricantes, o CAE pode ser aplicado sob condições adversas, como em períodos chuvosos e sem aquecimento, pois se trata de um material que pode apresentar alta trabalhabilidade, dispensando pintura de ligação e compactação, pois a densificação é feita pelo tráfego de veículos. Em Goiás, a Agência Goiana de Infraestrutura e Transportes (GOINFRA) têm projetos em andamento, tanto de construção, quanto de restauração, onde a mistura asfáltica do tipo CAE pode ser utilizada desde que as exigências do material seja a de um CA convencional, fato ainda não comprovado tecnicamente.

SANTANA e LOURENÇO [14] avaliaram duas amostras de CAE produzidas em Sergipe, que, de acordo com o fabricante, eram compostas de agregados enquadrados na Faixa $\mathrm{C}$ e de Cimento Asfáltico de Petróleo (CAP) do tipo 30/45. Os autores realizaram ensaios de caracterização dos materiais constituintes, testes mecanísticos e compararam os resultados com os valores pré-estabelecidos por norma e com os dados fornecidos pelo fabricante. Os autores obtiveram que as amostras de CAE estudadas apresentaram divergências na comparação dos resultados de caracterização com os dados fornecidos pelo fabricante e valores estabelecidos pela ES 031 [15]. Em relação aos resultados dos ensaios mecanísticos, os autores obtiveram que as amostras de CAE não atendem aos valores exigidos pelo Departamento Nacional de Infraestrutura de Transportes (DNIT) e possuem valores inferiores aos normalmente obtidos para misturas asfálticas convencionais, tanto para os corpos de prova compactados utilizando a metodologia Marshall, quanto para os compactados utilizando a metodologia Superpave. A verificação do enquadramento da granulometria das amostras na Faixa $\mathrm{C}$ do DNIT inticou que nenhuma das amostras atendia os limites estabelecidos.

OLIVEIRA [16] realizou parte da análise de uma amostra de CAE que será complementada neste artigo. De acordo com o fabricante, a amostra denominada de CAE-A se enquadraria na Faixa C do DNIT, seria composta de CAP 50/70 e foi produzida no entorno de Goiânia-GO. A preparação dos corpos de prova para os ensaios de desempenho foi realizada utilizando compactação por impacto, da metodologia Marshall. Além disso, foram executadas análises volumétrica e de desempenho mecânico considerando corpos de prova sem cura, com cura de 7 dias e com compactação com amostras previamente aquecidas a $60^{\circ} \mathrm{C}$, sendo a cura feita em ambiente fechado e sem exposição às intempéries. Como principais resultados, obteve-se que alguns parâmetros volumétricos e de desempenho não atenderam aos valores estabelecidos pela ES 031 [15]. O enquadramento na faixa não foi conclusivo, pois pode ter ocorrido segregação inadequada dos agregados durante o período de estocagem do material, o que se tornou mais evidente devido ao tamanho reduzido das amostras. Por fim, o estudo concluiu que a amostra CAE-A não apresentou boa trabalhabilidade a frio e que a compactação por impacto não é adequada para a preparação do material.

Internacionalmente, o CAE é conhecido comercialmente como EZ Street Asphalt, sendo que o estudo de MEJÍAS-SANTIAGO, VALLE-ROLDÁN e PRIDDY [17] indicou alta variabilidade nos parâmetros volumétricos (em termos de volume de vazios) e parâmetros mecânicos (MR e FN). Os autores concluíram que esse tipo de mistura tem baixa trabalhabilidade a frio e baixa resistência à deformação permanente, não sendo indicada para regiões de elevado volume de tráfego e com cargas pesadas.

Pouco conhecido em termos de comportamento mecânico, o CAE ainda é uma incógnita no meio científico devido à falta de estudos nacionais e internacionais, bem como pela inexistência de normas e especificações. As informações obtidas, até o momento, são aquelas fornecidas pelos fabricantes e de alguns estudos científicos. Logo, ainda não existe uma validação técnico-científica completa sobre a utilização desse tipo de mistura.

Assim, o principal objetivo deste artigo é analisar três misturas de CAE, avaliando sua viabilidade técnica para uso como revestimento asfáltico. Para isso, será apresentada a caracterização de seus componentes, suas composições, seus comportamentos utilizando a compactação por amassamento e seus desempenhos mecânicos sem e com cura, visando comparar os resultados obtidos com os parâmetros da mistura MCS (Micaxisto; Faixa C; Superpave) estudada por e BARROSO [12] e valores definidos em norma.

\section{MATERIAIS E MÉTODOS}

Os materiais estudados nesta pesquisa e os ensaios de laboratório realizados estão apresentados nos itens a seguir, sendo que na Figura 1 tem-se o fluxograma da metodologia da pesquisa, dividida em seis etapas prin- 
cipais: preparação das amostras, caracterização física, preparação dos corpos de prova, condições de ensaio e caracterização mecânica. Os ensaios foram realizados no Laboratório de Geotecnia da Universidade Federal de Goiás, no Laboratório de Estradas da Agência Goiana de Infraestrutura e Transportes (GOINFRA), no Laboratório de Infraestrutura Rodoviária na Universidade de Brasília (INFRALAB) e no Centro Tecnológico de FURNAS Centrais Elétricas S.A.

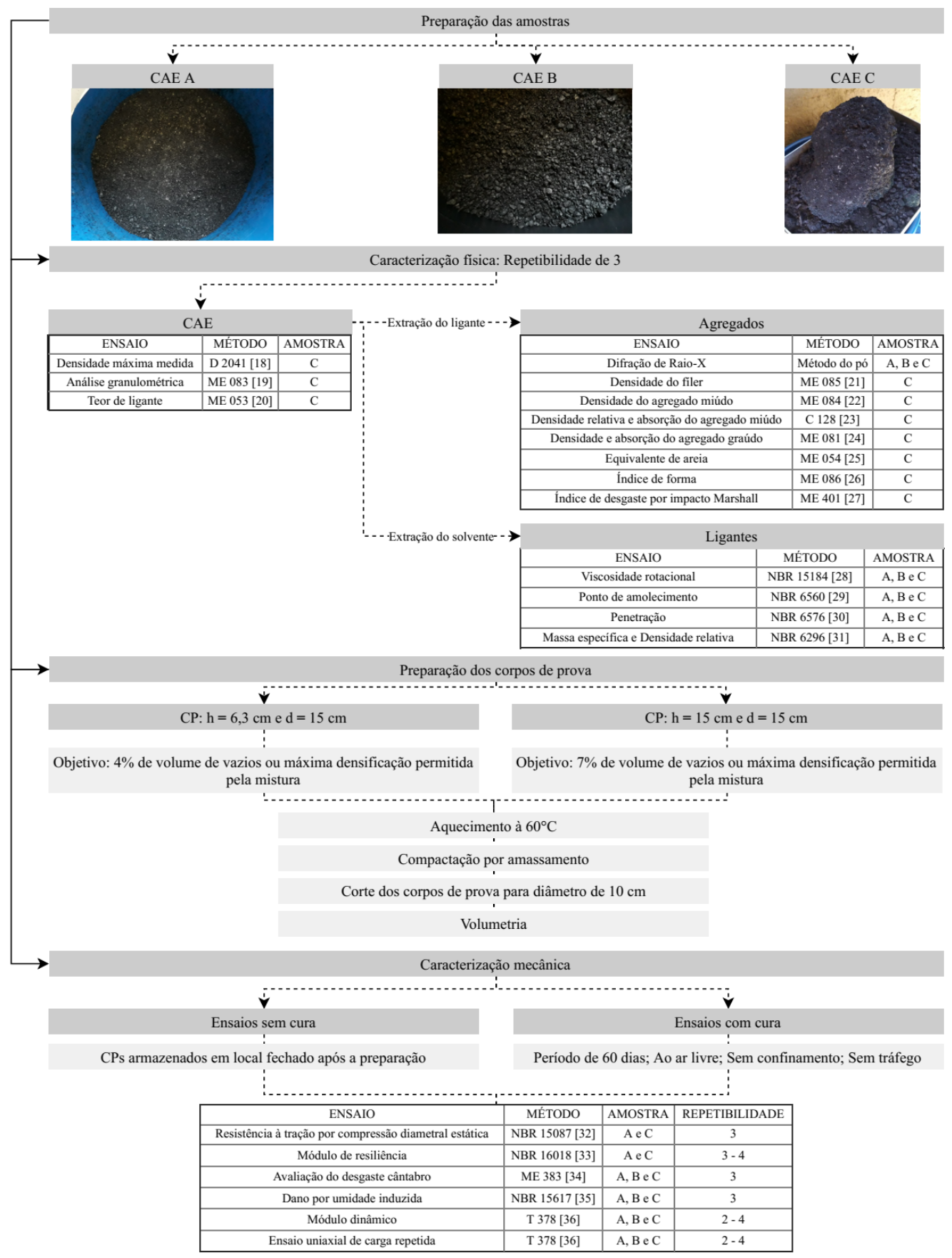

Figura 1: Fluxograma da metodologia da pesquisa. [19-27, 28-31, 32-36]

\subsection{Materiais}

Três amostras de Concreto Asfáltico Estocável (CAE-A, CAE-B e CAE-C) produzidas na região metropolitana de Goiânia-GO foram estudadas. De acordo com os fabricantes, os agregados estavam enquadrados na Faixa C da ES 031 [15]. Os agregados analisados foram obtidos a partir da extração do ligante das três amostras de CAE, conforme procedimentos da norma/ ME 053 [20]. Ressalta-se que as amostras CAE-A e CAE-B foram parcialmente estudadas por OLIVEIRA [16] e REZENDE [37]. 


\subsection{MÉTODOS}

\subsubsection{Preparação e Caracterização das Amostras}

As amostras de CAE foram destorroadas, homogeneizadas e quarteadas. Uma parte de cada amostra foi separada para que fosse feita a extração do ligante, de acordo com a norma ME 053 [20]. As amostras quarteadas foram armazenadas em recipientes plásticos e guardadas de forma que não recebessem luz solar.

A caracterização física dos agregados das amostras de CAE foi feita após a extração do ligante. Os ligantes foram obtidos com procedimento baseado na norma D5404 [38], que apresenta a metodologia de recuperação do ligante pelo método que utiliza o rotaevaporador. Como os ligantes extraídos de cada amostra estavam em soluções de concentrações diferentes de ligantes e solventes, seguiu-se um procedimento de extração equivalente para cada amostra, buscando obter ligantes com características próximas às iniciais. Os procedimentos de caracterização dos agregados e ligantes extraídos das amostras de CAE foram realizados de acordo com especificações brasileiras. As amostras de CAE foram caracterizadas de acordo com os procedimentos apresentados na Figura 1.

\subsubsection{Preparação dos Corpos de Prova}

Devido ao estudo preliminar realizado por OLIVEIRA [16] na amostra CAE-A, optou-se por preparar os corpos de prova $(\mathrm{CP})$ para os ensaios mecânicos aplicando a compactação por amassamento à $60^{\circ} \mathrm{C}$ para as amostras CAE-A, CAE-B e CAE-C.

$\mathrm{O}$ objetivo inicial era obter corpos de prova com o mesmo volume de vazios $\left(\mathrm{V}_{\mathrm{v}}\right)$ obtido por BARROSO [12] para um CA convencional produzido na região de estudo, visando comparação entre os resultados. Porém, conforme será explicado no item de resultados e discussões, não foi possível obter volume de vazios próximos para as amostras de CAE, pois as mesmas apresentaram pouca trabalhabilidade e baixa densificação. O procedimento para preparação dos corpos de prova consistiu, inicialmente, da obtenção do valor da Densidade Máxima Medida (Gmm) e da definição do tamanho do corpo de prova (65mm x $150 \mathrm{~mm}$ ). Em seguida, determinou-se a quantidade de material necessária para obter $4 \%$ de $\mathrm{V}_{\mathrm{w}}$ para cada amostra. $\mathrm{A}$ partir das quantidades de CAE determinadas e da altura desejada para o corpo de prova, foi possível dar início ao amassamento no compactador giratório. As amostras e os moldes foram estabilizados na temperatura de $60^{\circ} \mathrm{C}$ antes de dar início ao ensaio para viabilizar a compactação, visto que estudos anteriores indicaram que não é possível compactar o CAE sem esse aquecimento prévio $[14,16]$.

Após a moldagem de três corpos de prova para cada mistura, anotou-se o número de giros obtido para cada um deles e fez-se a determinação do volume de vazios real. No entanto, o volume de vazios obtido foi maior que o valor de $4 \%$ esperado. Sendo assim, utilizando os dados de densificação fornecidos pelo equipamento, optou-se por aumentar o número de giros e diminuir a quantidade de material a ser moldado em cada CP, de forma que, por tentativa e erro, se chegasse no volume de vazios mais próximo de $4 \%$ para cada amostra, respeitando os limites do equipamento. Com a determinação do número de giros e da quantidade de material necessários para moldar cada amostra, fez-se a moldagem dos corpos de prova visando obter quantidade suficiente para realização dos ensaios mecânicos. $\mathrm{O}$ mesmo procedimento foi realizado para obtenção dos corpos de prova maiores $(160 \mathrm{~mm} \times 150 \mathrm{~mm}$ ), os quais deveriam ter $7 \%$ de volume de vazios, que representa o início da vida do pavimento.

Após a moldagem dos corpos de prova, foi feito o corte do core, com diâmetro de 100mm, para realização dos ensaios. A retirada do core foi feita utilizando a extratora de corpos de prova e o molde de fixação. Além disso, os corpos de prova foram retificados visando obter a superfície mais regular possível em suas faces. O procedimento para determinar a volumetria dos corpos de prova foi feito anteriormente a cada ensaio por meio da balança hidrostática e da medição paquimétrica. Com os dados fornecidos pelo equipamento de compactação e as volumetrias foram realizadas análises de trabalhabilidade e densificação. Os ensaios de desempenho foram realizados considerando amostras sem cura e com cura de 60 dias, sendo este período escolhido de acordo com afirmações dos fabricantes de que o CAE apresenta melhoria em seu comportamento mecânico após compactação e cura. Durante o período de cura, os CPs foram expostos as intempéries, por meio de cura a céu aberto sem confinamento e sem aplicação de carga.

\subsubsection{Caracterização Mecânica}

Na Figura 1 estão apresentados os procedimentos realizados para a avaliação do desempenho mecânico e as respectivas normas que regem seus ensaios. A repetibilidade de cada ensaio variou de 2 a 4 CPs em função da dificuldade de obtenção dos mesmos. O nível de tensão adotado para a determinação do MR foi de $15 \%$ 
da tensão obtida no ensaio para determinação da RT por compressão diametral estática, sendo que o ensaio triaxial dinâmico foi realizado na prensa Universal Test Machine of $30 \mathrm{kN}$ (UTM-30).

O ensaio de determinação do módulo dinâmico (MD) também foi realizado na prensa UTM-30 para as frequências de $25 ; 20 ; 10 ; 5 ; 1 ; 0,5 ; 0,1 \mathrm{~Hz}$ e temperaturas de 4,4;21,1;37,8 e 54,4 ${ }^{\circ} \mathrm{C}$, de acordo com a norma T 378 [36], usando amostras de $150 \mathrm{~mm}$ x $100 \mathrm{~mm}$ preparadas no compactador giratório. Devido à pouca quantidade de material disponível para o estudo, optou-se por seguir a metodologia adotada por BARROSO [12], onde os corpos de prova do ensaio de MD foram reutilizados para o ensaio uniaxial de carga repetida. $\mathrm{O}$ ensaio uniaxial de carga repetida também foi realizado na prensa UTM-30 com uma tensão desviadora de $204 \mathrm{kPa}$ e tensão de contato de 10,2 kPa para determinação do FN. O pulso de carga atuou com a aplicação da carga por 0,1 segundos e o descanso de 0,9 segundos, sendo que o ensaio foi realizado na temperatura de $60^{\circ} \mathrm{C}$. Os critérios de parada adotados foram 10000 ciclos de aplicação de carga ou 50000 microstrain de deformação. Por fim, também foram realizados o ensaio de Desgaste Cântabro com os corpos de prova utilizados na determinação do MR e o ensaio de Dano por Umidade Induzida.

\section{RESULTADOS E DISCUSSÕES}

\subsection{Caracterização dos agregados}

Os agregados obtidos após a extração do ligante das misturas de CAE foram caracterizados e os principais resultados obtidos estão apresentados na Tabela 1.

Tabela 1: Caracterização dos agregados.

\begin{tabular}{l|c|c|c|c}
\multirow{2}{*}{ PROPRIEDADES } & \multicolumn{2}{|c|}{ REZENDE [37] } & \multirow{2}{*}{ CAE-C } & \multirow{2}{*}{ ES 031 [15] } \\
\cline { 2 - 4 } & CAE-A & CAE-B & & \\
\hline Densidade do fíler $\left(\mathrm{g} / \mathrm{cm}^{3}\right)$ & 2,82 & 2,70 & 2,68 & - \\
\hline Densidade real do agregado miúdo $\left(\mathrm{g} / \mathrm{cm}^{3}\right)$ & 2,78 & 2,78 & 2,72 & - \\
\hline Densidade aparente do agregado miúdo $\left(\mathrm{g} / \mathrm{cm}^{3}\right)$ & 2,70 & 2,77 & 2,66 & - \\
\hline Absorção do agregado miúdo $(\%)$ & 2,6 & 1,0 & 2,2 & - \\
\hline Densidade real do agregado graúdo $\left(\mathrm{g} / \mathrm{cm}^{3}\right)$ & 2,77 & 2,76 & 2,73 & - \\
\hline Densidade aparente do agregado graúdo $\left(\mathrm{g} / \mathrm{cm}^{3}\right)$ & 2,66 & 2,70 & 2,63 & - \\
\hline Absorção do agregado graúdo $(\%)$ & 1,5 & 0,8 & 1,4 & - \\
\hline Equivalente de areia $(\%)$ & 80 & 87 & 78 & $>55 \%$ \\
\hline Índice de degradação Marshall $(\%)$ & 3 & - & 4 & $<5 \%$ \\
\hline Abrasão Los Angeles $(\%)$ & - & 33 & - & $<50 \%$ \\
\hline Índice de forma - Graduação D & 0,69 & 0,61 & 0,62 & $>0,5$ \\
\hline
\end{tabular}

Os resultados dos ensaios de difração de Raios-X (DRX) obtidos para as amostras A e B (Figura 2), indicam a possibilidade desses agregados serem do tipo micaxisto, gnaisse e outras rochas, porém, alinhando os resultados de DRX com uma observação macroscópica da rocha e a informação de que estes agregados possuem origem nas pedreiras da região de Goiânia-GO, pode-se afirmar que esses agregados são micaxistos. Já a amostra CAE-C é um calcário, composto principalmente por calcita, quartzo e dolomito. De acordo com BERNUCCI et al. [1], as rochas calcárias têm alta porcentagem de materiais macios, que tendem ao polimento. Essa afirmação pode ser confirmada no ensaio de degradação Marshall, realizado nas amostras CAE-A e CAE-C, que indicou que os agregados da amostra CAE-C são menos resistentes.

As amostras de agregados CAE-A e CAE-B apresentaram resultados semelhantes para a maioria das propriedades, sendo que os resultados que mais divergiram foram a absorção dos agregados, o equivalente de areia e o índice de forma. GOUVEIA [39] concluiu em seu estudo que quanto menor a densidade aparente de agregados de mesma origem maior a absorção de água e de asfalto, o que foi observado para os agregados 
das amostras CAE-A e CAE-B. As amostras CAE-A e CAE-C apresentaram maior absorção em seus agregados, o que é um indicativo da necessidade de maior teor de ligante na mistura. Os resultados de equivalente de areia indicam que a amostra CAE-C pode ter maior potencial à danos por umidade e menor adesividade entre agregados e ligantes. Por fim, os resultados de índice de forma permitem concluir que os agregados da amostra CAE-A tem formato mais lamelar quando comparado com os agregados das amostras CAE-B e CAE-C, o que pode indicar menor trabalhabilidade e maior necessidade de ligante asfáltico na mistura.

Devido à quantidade reduzida de agregados obtidos após a extração dos ligantes, foram feitos dois tipos de ensaios para avaliar a resistência dos agregados, sendo o desgaste Los Angeles e a degradação por compactação Marshall. Analisando os parâmetros dos agregados das misturas de CAE com aqueles sugeridos na norma ES 031 [15], pode-se afirmar que o CAE atende aos limites de desgaste Los Angeles, degradação por compactação Marshall, equivalente de areia e índice de forma.
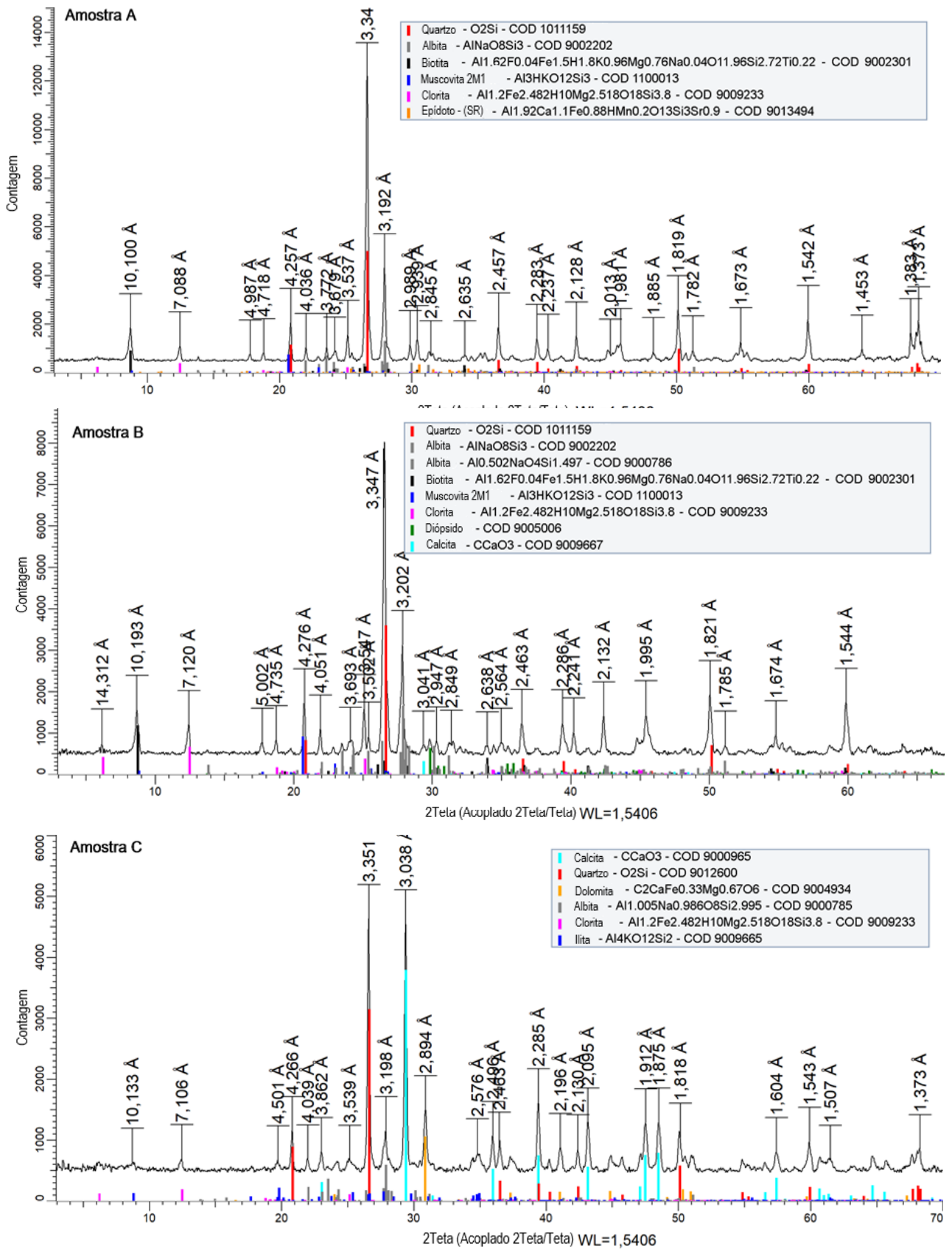

Figura 2: Resultados de DRX: A) Difratograma do agregado da amostra CAE-A; B) Difratograma do agregado da amostra CAE-B; C) Difratograma do agregado da amostra CAE-C.8 [19-27, 28-31, 32-36] 
Comparando os resultados obtidos para os agregados CAE-A e CAE-B com os agregados estudados por BARROSO [12] e apresentados na Tabela 2, nota-se que as absorções, o equivalente de areia e a abrasão Los Angeles são maiores e que o índice de forma é menor. Esses resultados indicam que os agregados das misturas CAE-A e CAE-B podem apresentar melhor adesividade com o ligante e melhor intertravamento entre seus grãos.

Tabela 2: Caracterização do micaxisto (adaptado de BARROSO [12]).

\begin{tabular}{l|c|c|c}
\hline PROPRIEDADES & BRITA 1 & BRITA 0 & PÓ DE PEDRA \\
\hline Densidade real do agregado $\left(\mathrm{g} / \mathrm{cm}^{3}\right)$ & 2,78 & 2,78 & 2,79 \\
\hline Densidade aparente do agregado $\left(\mathrm{g} / \mathrm{cm}^{3}\right)$ & 2,73 & 2,66 & 2,76 \\
\hline Absorção do agregado (\%) & 0,7 & 1,3 & 0,8 \\
\hline Equivalente de areia (\%) & - & - & 68 \\
\hline Abrasão "Los Angeles" (\%) - Graduação C & & 28,7 & - \\
\hline Índice de forma (\%) - Graduação D & \multicolumn{2}{|c|}{0,76} & - \\
\hline
\end{tabular}

\subsection{Caracterização dos ligantes}

Os ligantes de CAE foram obtidos a partir de suas misturas pela extração utilizando o método Rotarex, sendo que estes foram sujeitos a variações de temperatura para a posterior extração do solvente. Logo, considerouse que esses ligantes foram envelhecidos durante o processo. Além disso, para esta análise, desconsiderou-se a presença de aditivo na composição dos ligantes, sendo que as classificações e análises foram feitas considerando ligantes convencionais. Porém, sabe-se que a presença desse aditivo de composição e quantidade desconhecidos pode alterar as propriedades do ligante e seu comportamento reológico. Os ligantes extraídos das misturas de CAE apresentaram as propriedades apresentadas na Tabela 3.

Tabela 3: Caracterização laboratorial dos ligantes extraídos das misturas de CAE.

\begin{tabular}{l|c|c|c|c}
\hline PROPRIEDADES & CAE-A & CAE-B & CAE-C & EM 095 [40] \\
\hline Massa específica $\left(\mathrm{g} / \mathrm{cm}^{3}\right)$ & 1,022 & 1,020 & 1,025 & - \\
\hline Penetração retida $(\%)$ & 144 & 64 & 84 & 55 (mínimo) \\
\hline Ponto de amolecimento $\left({ }^{\circ} \mathrm{C}\right)$ & 51,9 & 54,5 & 57,4 & +8 (máximo) \\
\hline Susceptibilidade térmica - IP & 0,198 & $-1,092$ & 0,089 & - \\
\hline Viscosidade Brookfield $135^{\circ} \mathrm{C}(\mathrm{cP})$ & 339,5 & 614,8 & 917,3 & - \\
\hline Viscosidade Brookfield $150^{\circ} \mathrm{C}(\mathrm{cP})$ & 171 & 283,3 & 384,5 & - \\
\hline Viscosidade Brookfield $177^{\circ} \mathrm{C} \mathrm{(cP)}$ & 65,78 & 94,58 & 119,7 & - \\
\hline
\end{tabular}

A partir dos resultados foi possível classificar os ligantes com base nos resultados obtidos para os ensaios de penetração após o envelhecimento a curto prazo. A norma EM 095 [40] estabelece que a penetração retida mínima após o envelhecimento para o CAP 50/70 deve ser de 55\%, logo, os ligantes podem ser classificados como CAP 50/70. O ligante CAE-A apresentou elevado valor de penetração retida, indicando que o aditivo presente no mesmo pode ter impedido o envelhecimento do ligante ou que ainda há solvente misturado ao ligante.

Os valores de IP indicam que o ligante CAE-B é mais susceptível as variações térmicas e o ligante CAE-A é menos susceptível as variações térmicas, sendo que os três ligantes estão dentro da faixa de susceptibilidade térmica aceitável. Apesar de os valores de penetração indicarem que o ligante CAE-B possui maior consistência que os outros ligantes, esse valor não é representativo para situações em campo, devido à temperatura de ensaio ser $25^{\circ} \mathrm{C}$. Logo, avaliando-se a consistência dos ligantes pela relação entre a penetração e a viscosidade, pode-se concluir que o ligante da amostra CAE-C possui maior consistência, devido ao seu bai- 
xo valor de penetração e alta viscosidade.

O ligante CAE-C foi o que apresentou maiores valores de viscosidade, comprovando sua maior consistência em relação aos demais. Além disso, comparando-se os valores de viscosidades obtidos com os valores apresentados no estudo de BARROSO et al. [41] para ligantes de mesma especificação, nas condições virgem e envelhecido (Tabela 4 e Figura 3), percebe-se que os ligantes CAE-B e CAE-C apresentam maiores viscosidades, o que pode ser um indicativo de que o processo de extração dos ligantes causa envelhecimento maior que a avaliação realizada após as amostras serem colocadas na Estufa de Película Delgada Rotacional (RTFOT).

Tabela 4: Parâmetros do CAP 50/70 nas condições virgem e envelhecido obtidos por BARROSO et al. [41].

\begin{tabular}{l|c|c}
\multirow{2}{*}{ PROPRIEDADES } & BARROSO et al. [41] & BARROSO et al. [41] \\
\cline { 2 - 3 } & CAP 50/70 VIRGEM & CAP 50/70 ENVELHECIDO \\
\hline Massa específica $\left(\mathrm{g} / \mathrm{cm}^{3}\right)$ & 1,002 & - \\
\hline Penetração $(0,1 \mathrm{~mm})$ e Penetração retida $(\%)$ & 61 & $80 \%$ \\
\hline Ponto de amolecimento $\left({ }^{\circ} \mathrm{C}\right)$ & 47,7 & 50,0 \\
\hline Viscosidade Brookfield $135^{\circ} \mathrm{C}(\mathrm{cP})$ & 387,2 & 471 \\
\hline Viscosidade Brookfield $150^{\circ} \mathrm{C}(\mathrm{cP})$ & 164,87 & 222 \\
\hline Viscosidade Brookfield $177^{\circ} \mathrm{C}(\mathrm{cP})$ & 61,27 & 77,43 \\
\hline
\end{tabular}

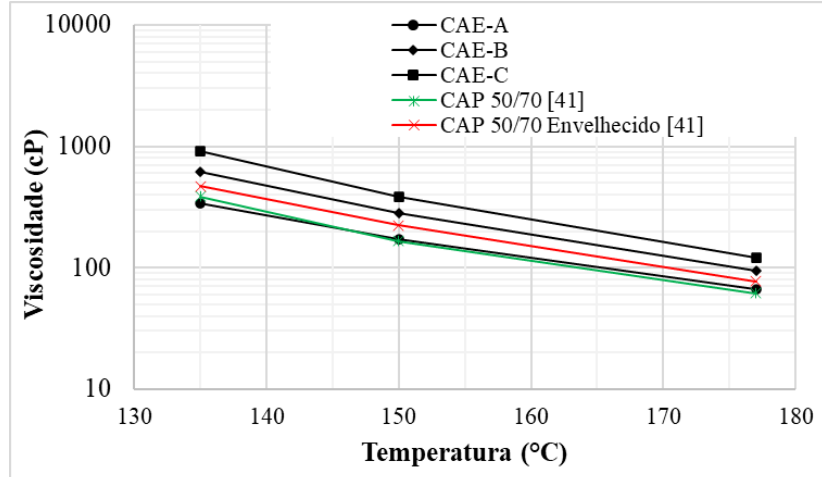

Figura 3: Viscosidades dos ligantes de CAE comparadas com as viscosidades obtidas em ligantes convencionais estudados em Goiás.

\subsection{Caracterização física das misturas}

As misturas CAE-A e CAE-B foram caracterizadas nos estudos de OLIVEIRA [16] e REZENDE [37], respectivamente, sendo os resultados apresentados na Tabela 5 e Figura 4.

Tabela 5: Caracterização das misturas de CAE e micaxisto-Faixa C-metodologia Superpave (MCS).

\begin{tabular}{l|c|c|c|c}
\hline PROPRIEDADES & CAE-A [16] & CAE-B [37] & CAE-C & MCS [12] \\
\hline Enquadramento granulométrico & Faixa C & Faixa C & Faixa C & Faixa C \\
\hline Teor de ligante (\%) & 6,6 & 5,7 & 5,8 & 5,6 \\
\hline Densidade máxima medida $[\mathrm{Gmm}]\left(\mathrm{g} / \mathrm{cm}^{3}\right)$ & 2,532 & 2,546 & 2,514 & 2,534 \\
\hline
\end{tabular}

As composições granulométricas das três amostras de CAE indicaram que a amostra CAE-C apresenta 
maior quantidade de finos, se aproximando do limite superior da Faixa C da norma ES 031 [15] e que as amostras CAE-A e CAE-B têm composições granulométricas semelhantes. A composição granulométrica no formato proposto pela metodologia Superpave evidenciou a diferença da amostra CAE-C em relação às outras amostras, sendo que de acordo com VAVRIK et al. [7] curvas granulométricas com formato em S indicam dificuldade de compactação. Além disso, foi possível observar que as curvas granulométricas atendem os pontos de controle para cada tamanho máximo nominal especificado.

Em relação à mistura composta de micaxisto na Faixa $\mathrm{C}$ e compactada de acordo com a metodologia Superpave (MCS) estudada por BARROSO [12], as amostras CAE-A e CAE-B foram as que apresentaram as composições granulométricas mais próximas, porém o teor de ligante foi menor para a mistura MCS, sendo que isto pode ser devido à diferença entre as metodologias de dosagem Marshall e Superpave. O teor de ligante da amostra CAE-A foi o maior dentre as três amostras. Esse fato já era esperado devido à maior absorção e índice de forma do agregado. Esperava-se maior teor de ligante na amostra CAE-C, quando comparada com a amostra CAE-B, visto que a amostra CAE-C tem maior absorção em seus agregados e maior quantidade de finos, tendo índice de forma próximo ao da amostra CAE-B. Porém, o teor de ligante foi praticamente o mesmo.

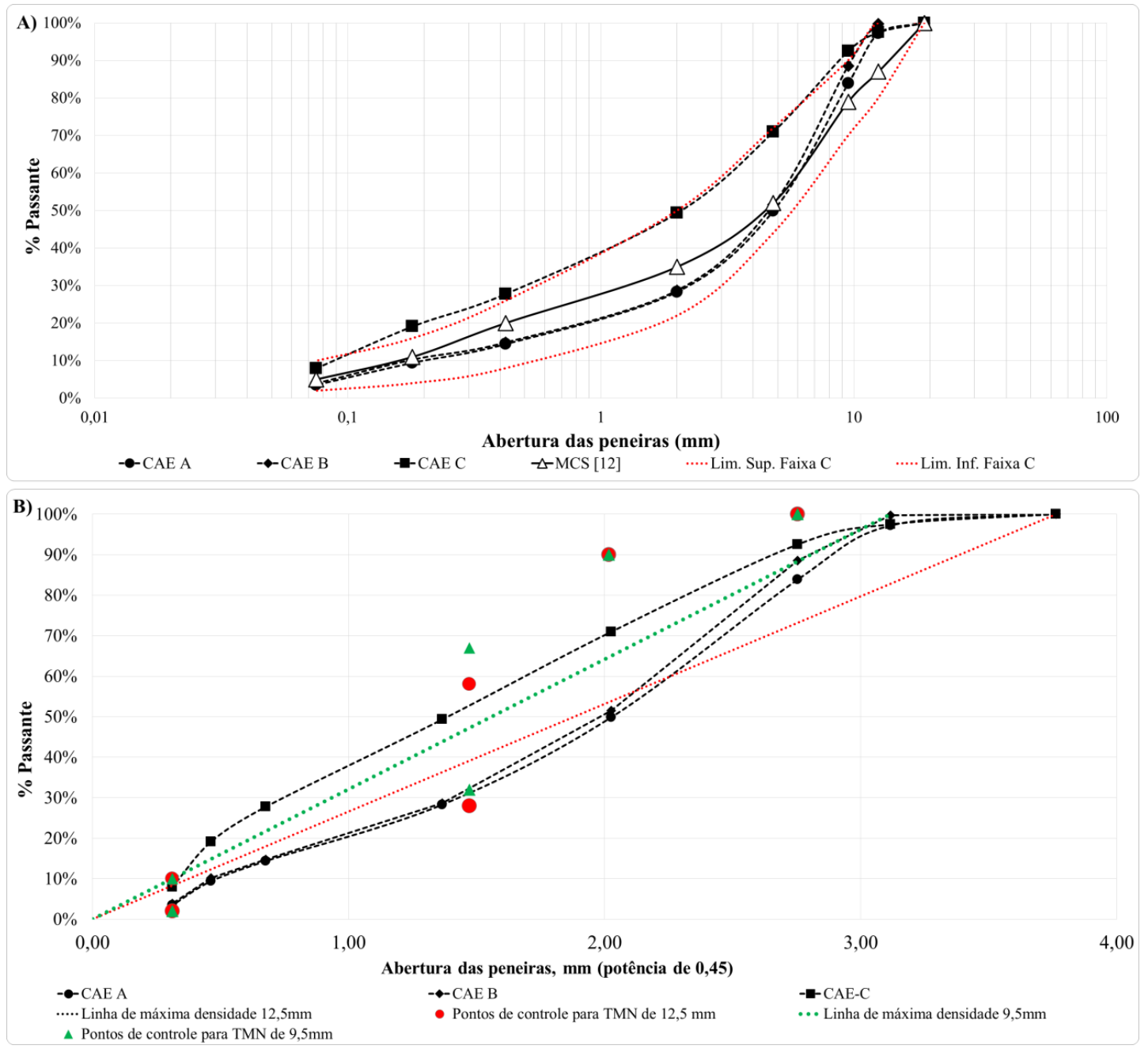

Figura 4: A) Composição granulométrica, conforme ES 031 [15]; B) Composição granulométrica nos padrões Superpave para o CAE-A, CAE-B e CAE-C, conforme M 323 [42].

Além da análise granulométrica determinada de acordo com a norma ES 031 [15] e da análise apresentada conforme a metodologia Superpave, foi realizada a análise pelo método Bailey [7] (Tabela 6) e pelo método FAD (Tabela 7). De acordo com VAVRIK et al. [7], valores de AG próximos de 1 obtidos nas misturas CAE-A e CAE-B, indicam que elas não estão bem intertravada, apresentando dificuldades na compactação e tendência ao aparecimento de corrugações com a aplicação das cargas de tráfego. Já para valor de 
AG abaixo dos limites estabelecidos obtido para CAE-C, pode-se ter segregação na mistura, tendo áreas com excesso de agregado graúdo. Para valor de GAF acima dos valores estabelecidos obtido para CAE-C, tem-se excesso de porção fina do agregado fino. Por fim, para valores de FAF acima de 0,5, obtidos para as amostras CAE-A e CAE-B, o autor afirma que a graduação possui excesso de finos, o que torna a mistura mais deformável.

Para a análise do método FAD considerou-se duas situações, sendo uma com o VAM obtido para a dosagem e uma com o VAM obtido neste estudo. O VAM de projeto foi calculado considerando-se $4 \%$ de vazios, pois supõe-se que as misturas de CAE tenham sido dosadas de acordo com o método da norma ES 031 [15]. A análise da porosidade FAD apresentou que as misturas de CAE têm porosidades maiores que $52 \%$ para as duas situações avaliadas, podendo ser classificadas como misturas marginais, sendo que, de acordo com GREENE et al. [43], esse fato pode indicar baixa resistência à deformação permanente.

Tabela 6: Valores obtidos para as misturas de CAE de acordo com o método Bailey.

\begin{tabular}{l|c|c|c|c}
\hline MISTURAS & REGIDO & AG & GAF & FAF \\
\hline CAE-A (12,5) & Agregado Graúdo & 0,905 & 0,432 & 0,650 \\
\hline CAE-B (12,5) & Agregado Graúdo & 1,000 & 0,434 & 0,653 \\
\hline CAE-C (9,5) & Agregado Miúdo & 0,512 & 0,537 & - \\
\hline MCS (19,0) [12] & Agregado Graúdo & 1,16 & 0,57 & 0,15 \\
\hline
\end{tabular}

Nota: $\mathrm{AG}=$ Proporção de agregado graúdo; GAF = Proporção graúda do agregado fino; FAF = Proporção fina do agregado fino; MCS = Micaxisto - Faixa C - Superpave.

Tabela 7: Análise das misturas pelo método FAD.

\begin{tabular}{l|c|c|c|c}
\hline PARÂMETROS & CAE-A & CAE-B & CAE-C & MCS [12] \\
\hline FAD & $9,5-2,36$ & $9,5-2,36$ & $6,3-2,36$ & $2,36-1,18$ \\
\hline Porosidade (VAM projeto) & $54 \%$ & $54 \%$ & $85 \%$ & 76,7 \\
\hline Porosidade (VAM real) & $55 \%$ & $58 \%$ & $90 \%$ & 76,7 \\
\hline
\end{tabular}

Nota: FAD = Faixa de agregados dominantes; VAM = Vazio do agregado mineral; MCS = Micaxisto - Faixa C - Superpave .

\subsection{Densificação e Volumetria}

Neste estudo, considerou-se que as amostras de CAE tenham sido dosadas conforme metodologia Marshall, com compactação por impacto, pelo fato dessa ainda ser a metodologia mais utilizada nas usinas de asfalto existentes na região de estudo. No entanto, como OLIVEIRA [16] indicou que não é possível utilizar a compactação por impacto para a produção de corpos de prova de CAE em laboratório, nesta pesquisa as amostras de CAE foram compactadas utilizando o compactador giratório, com reaquecimento à $60^{\circ} \mathrm{C}$. A partir desse procedimento foram obtidos parâmetros como o CDI e o Locking point (LP). Por fim, foi realizada a volumetria dos corpos de prova para obtenção do volume de vazios. Os resultados obtidos para as amostras de CAE foram comparadas com os resultados da mistura MCS estudada por BARROSO [12]. Os parâmetros de cada mistura estão apresentados na Tabela 8 .

Comparando-se as três misturas de CAE, nota-se que a amostra CAE-A foi a que apresentou menores valores de CDI, o que indica que o CAE-A tem a melhor trabalhabilidade dentre as três amostras, fato justificado pelo seu maior teor de ligante e consistência do mesmo. De acordo com MAHMOUD e BAHIA [9], misturas com valores de CDI menores que 100 têm trabalhabilidade aceitáveis. Portanto, as misturas CAE-B e CAE-C não são aceitáveis quanto à trabalhabilidade, tendo valores de CDI muito acima do limite proposto, o que pode ser um indicativo de que essas misturas estão envelhecidas. As misturas CAE-A e CAE-B apresentaram curvas granulométricas parecidas e mesmo tipo de agregado. Porém, a amostra CAE-A apresentou melhor trabalhabilidade, apesar de ter agregados com índice de forma menos cúbicos; a menor trabalhabilidade da mistura CAE-B pode ser devido à falta de ligante nesta mistura.

$\mathrm{O}$ número de giros aplicado na amostra CAE-A foi igual ao número de giros aplicado na amostra CAE-C; porém, a amostra CAE-A apresentou menor volume de vazios e menor CDI, o que pode ser devido à granulometria e ao maior teor de ligante da amostra CAE-A. O volume de vazios obtido para a amostra CAE- 
B foi próximo ao volume de vazios obtido para a amostra CAE-C; no entanto, o número de giros aplicado na amostra CAE-B foi maior, o que indica que esta tem maior dificuldade na densificação, fato comprovado pelo seu alto valor de CDI. Além disso, o alto valor de CDI para a amostra CAE-B confirmou a análise realizada pelo método Bailey.

Tabela 8: Parâmetros de densificação e volumetria.

\begin{tabular}{l|c|c|c|c}
\hline PARÂMETROS & CAE-A (12,5) & CAE-B (12,5) & CAE-C (9,5) & MCS (19,0) [12] \\
\hline Número de giros & 250 & 380 & 250 & 100 \\
\hline CDI & 95 & 1280 & 630 & 34 \\
\hline Locking Point (LP) & 42 & 45 & 40 & 4,0 \\
\hline Vv $-6,3 \mathrm{~cm}(\%)$ & 6,0 & 8,7 & 8,1 & 2,432 \\
\hline Gmb $\left(\mathrm{g} / \mathrm{cm}^{3}\right)$ & 2,378 & 2,327 & 2,308 & - \\
\hline Vv no LP $(\%)$ & 7,8 & 11,9 & 12,0 & 4,0 \\
\hline Vv de projeto $(\%)$ & 4,0 & 4,0 & 4,0 & 13,5 \\
\hline VAM real (\%) & 16,0 & 19,0 & 17,7 & 13,5 \\
\hline VAM de projeto (\%) & 15,2 & 15,6 & 14,1 & 70,4 \\
\hline VFA real (\%) & 68,0 & 58,4 & 54,8 & 70,4 \\
\hline VFA de projeto (\%) & 73,7 & 74,4 & 71,6 & \\
\hline
\end{tabular}

Nota: Vv = Volume de vazios; CDI = Índice de densificação na construção; VAM = Vazios do agregado mineral; VFA = Vazios preenchidos com asfalto; ${ }^{1} \mathrm{O}$ volume de vazios de projeto foi suposto em 4,0\% pois acredita-se que as misturas de CAE tenham sido dosadas de acordo com a metodologia Marshall.

O Locking Point (LP) pode ser entendido como o giro no qual esqueleto mineral se trava, sendo que os giros seguintes a este podem causar degradação do agregado e causam pouca densificação adicional [44]. Analisando as misturas de CAE percebe-se que a mistura CAE-A já havia se densificado $87 \%$ no LP; já as misturas CAE-B e CAE-C se densificaram em $74 \%$, indicando que o volume de vazios tem pouca redução após o LP e que pode ter ocorrido degradação do agregado e consequente alteração da granulometria.

A norma M 323 [42] estabelece valores limites de $\mathrm{V}_{\mathrm{v}}$, VAM e VFA de acordo com o tamanho nominal máximo (TMN) e o tráfego (Tabela 9). Analisando as amostras estudadas, percebe-se que os valores VAM de projeto e VFA de projeto das misturas CAE-A e CAE-B atendem aos limites; porém, a amostra CAE-C possui valor de VAM de projeto abaixo do limite, o que pode indicar maior valor de resistência à deformação permanente [45]. Os valores de VAM reais indicam que as misturas de CAE têm um excesso de volume de vazios, pois estão com mais de $2 \%$ acima do valor mínimo, tendo susceptibilidade à deformação permanente, de acordo com M 323 [42]. Os valores VFA reais confirmam o excesso de volume de vazios, pois as misturas CAE-B e CAE-C estão abaixo dos limites estabelecidos.

Tabela 9: Parâmetros propostos na norma M 323 [43].

\begin{tabular}{c|c}
\hline PARÂMETROS & SUPERPAVE \\
\hline Vv $(\%)$ & 4 \\
\hline VAM mínimo (\%) & $14($ TMN 12,5) - 15 (TMN 9,5) \\
\hline VFA (\%) & $65-75$ \\
\hline
\end{tabular}

Nota: Vv = Volume de vazios; VAM = Vazio do agregado mineral; VFA = Vazios preenchidos com asfalto; TMN = Tamanho máximo nominal.

Em relação aos valores de $\mathrm{V}_{\mathrm{v}}$, as amostras de CAE não atingiram o valor esperado de projeto (4\%) para os corpos de prova com altura de $6,3 \mathrm{~cm}$. Os corpos de prova de $15 \mathrm{~cm}$, utilizados nos ensaios de MD e FN deveriam ter $7 \%$ de volume de vazios, o que também não foi alcançado devido à elevada variação dentre os corpos de prova produzidos, conforme apresentado na Tabela 10. Logo, confirma-se que o CAE não apresenta comportamento de densificação igual dentre seus corpos de prova, sendo que isso pode ocorrer devido à segregação da mistura durante o quarteamento ou devido à produção e estocagem do CAE na usina. NOGUEIRA [46] verificou que houve variabilidade na granulometria de 12 misturas asfálticas, com mesma dosagem, produzidas na mesma usina. Portanto, acredita-se que a produção do CAE e a estocagem em pilhas causa variabilidade na granulometria do CAE e consequente variação no volume de vazios.

A mistura MCS estudada por BARROSO [12] apresentou menor valor de CDI, indicando que a mesma tem melhor trabalhabilidade e se densifica com menor número de giros que as amostras de CAE. Logo, confirma-se que o CAE não tem a trabalhabilidade de um CA convencional. Deve-se ressaltar que as 
amostras de CAE foram compactadas na temperatura de $60^{\circ} \mathrm{C}$, sendo que, de acordo com os fabricantes, os mesmos teriam boa trabalhabilidade à frio, o que não ocorreu.

Tabela 10: Volumes de vazios, desvios padrões e coeficientes de variância para as amostras de CAE.

\begin{tabular}{c|c|c|c|c|c|c}
\hline MISTURAS & $\mathbf{V}_{\mathbf{v}}-\mathbf{6 , 3 C M}(\%)$ & D.P. (\%) & C.V. (\%) & $\mathbf{V}_{\mathbf{v}}-\mathbf{1 5 C M}$ (\%) & D.P. (\%) & C.V. (\%) \\
\hline CAE-A & 6,0 & 0,5 & 8,6 & 5,4 & 0,9 & 16,1 \\
\hline CAE-B & 8,7 & 0,7 & 7,7 & 6,6 & 0,6 & 9,2 \\
\hline CAE-C & 8,1 & 0,3 & 4,1 & 6,6 & 0,5 & 6,9 \\
\hline
\end{tabular}

Nota: $\mathrm{Vv}=$ Volume de vazios; $\mathrm{DP}=$ Desvio padrão $\mathrm{CV}=$ Coeficiente de variância.

JUNG [47] realizou um estudo no qual correlacionou o efeito do envelhecimento do ligante com o envelhecimento de misturas asfálticas, confirmando que o envelhecimento da mistura apresenta o mesmo mecanismo que o envelhecimento do ligante, ou seja, a oxidação dos compostos do ligante faz com que sua flexibilidade diminua. Portanto, a baixa trabalhabilidade observada nas misturas CAE-B e CAE-C também pode ter ocorrido devido ao provável envelhecimento das misturas durante a estocagem e reaquecimento para a compactação, visto que era esperada maior trabalhabilidade devido à presença do aditivo nas misturas de CAE. Ressalta-se que as misturas de CAE foram recebidas e armazenadas em recipientes lacrados e guardadas em ambiente fechado no laboratório e que o grupo de pesquisa não teve autorização para participar da coleta das amostras in loco. Logo, os resultados obtidos podem indicar que as misturas CAE-B e CAE-C sejam misturas mais antigas, provavelmente com datas de fabricações anteriores.

Como as amostras de CAE foram produzidas por empresas distintas e apresentaram propriedades físicas e volumétricas diferentes, foi realizada análise da variância (ANOVA) para testar a igualdade entre as três amostras baseada na análise das variâncias dos volumes de vazios. Verificou-se que as três amostras são diferentes entre si, quando avaliadas em relação à variância do volume de vazios, para ensaios com corpos de prova com dimensões de $6,3 \mathrm{~cm}$ de altura e $15 \mathrm{~cm}$ de altura. Além disso, para verificar se todas as amostras são diferentes entre si ou se apenas uma das amostras se distingue das outras realizou-se o Teste de Tukey com nível de confiança de 5\%. A partir do teste estatístico verificou-se que as amostras CAE-B e CAE-C não são significativamente diferentes; já a amostra CAE-A apresenta diferença significativa em relação as outras amostras. Por esse motivo os resultados mecânicos obtidos para a amostra CAE-A apresentados a seguir não foram comparados com os parâmetros mecânicos determinados para as amostras CAE-B e CAE-C.

\subsection{Caracterização mecânica}

A Tabela 11 apresenta parte dos resultados mecânicos obtidos para as amostras de CAE e o resultado apresentado por BARROSO [12] para a mistura MCS. A norma ES 031 [15] estabelece que a RT deve ser maior que 0,65 MPa. Das três amostras de CAE estudadas, apenas a amostra CAE-C, para as condições sem cura (SC) e com cura (CC), atendeu o valor mínimo de norma. No entanto, o resultado obtido foi menor que o valor encontardo para um CA convencional produzido na região (MCS). Esses resultados indicam que, em termos de RT, o CAE, na forma que vem sendo produzido, não pode ser igualado a um CA convencional, apresentando limitações práticas de utilização.

Tabela 11: Resultados mecânicos.

\begin{tabular}{l|c|c|c|c|c|c|c}
\hline MISTURA & RT (MPA) & MR (MPA) & $\begin{array}{c}\text { DC } \\
\text { (\%) }\end{array}$ & RTT (\%) & FN (CICLOS) & íNDICE FN & MR/RT \\
\hline CAE-A SC & 0,43 & 1631 & 4 & 84 & 139 & 49,07 & 3793 \\
\hline CAE-A CC & 0,39 & 1553 & 5 & 94 & 128 & 58,02 & 3982 \\
\hline CAE-B SC & $0,48[37]$ & $2238[37]$ & 11 & 99 & 151 & 42,11 & 4144 \\
\hline CAE-B CC & $0,54[37]$ & $2638[37]$ & 14 & 102 & 202 & 34,62 & 4885 \\
\hline CAE-C SC & 1,05 & 5140 & 10 & 50 & 2179 & 5,31 & 4895 \\
\hline CAE-C CC & 0,98 & 5965 & 10 & 63 & 1502 & 7,04 & 6087 \\
\hline MCS [12] & 1,40 & 7658 & 6 & 35 & 118 & 69,12 & 5470 \\
\hline
\end{tabular}

Nota: $\mathrm{SC}=\mathrm{Sem}$ cura; $\mathrm{CC}=\mathrm{Com}$ cura; $\mathrm{MCS}=$ Micaxisto - faixa $\mathrm{C}$ - Superpave RT = Resistência à tração; $\mathrm{MR}$ = Módulo de resiliência; $\mathrm{DC}=$ Desgaste cântabro; RTT $=$ Resistência à tração retida; FN = Flow Number .

BERNUCCI et al. [1] afirmam que os valores de MR de misturas asfálticas variam entre 2000 e 8000 $\mathrm{MPa}$, sendo os valores menores para misturas mais flexíveis e os valores maiores para misturas com asfaltos de consistência dura. A amostra de CAE-A apresentou valor de MR inferior a $2000 \mathrm{MPa}$ o que demenstra seu 
comportamento resiliente insatisfatório. Conforme já apresentado, o ligante existente na amostra CAE-C tem menor valor de penetração e maiores valores de viscosidade; logo, sob esse aspecto, seria esperado que seu valor de MR fosse maior que o da amostra CAE-B, conforme constatado na Tabela 11. Porém, quando se compara as rochas de origem dos agregados, esperava-se que a amostra CAE-B obtivesse maiores valores de MR, pois seus agregados são compostos por minerais mais duros que os minerais dos agregados da amostra CAE-C. Verificou-se, ainda, que os valores de MR foram menores para as amostras de CAE, quando comparadas com a amostra MCS, provavelmente devido ao menor valor de VAM da amostra MCS, ao menor volume de vazios e a maior temperatura de compactação utilizada na mistura MCS. Novamente, constata-se a limitação de comportamento mecânico do CAE atualmente produzido quando comparado com um CA convenciconal.

Os resultados de DC foram satisfatórios, sendo que os valores obtidos para a amostra CAE-A estão próximos ao valor de um CA convencional. As amostras CAE-B e CAE-C apresentam valores maiores, sendo que isto pode ser um indicativo da baixa adesão entre os agregados e ligantes nessas misturas. A amostra CAE-B apresentou elevados valores de desgaste cântabro, o que confirma a hipótese de que essa mistura é constituída de teor de ligante asfáltico insuficiente. Quanto aos resultados de RTT, a norma D 4867 [48] estabelece que valores mínimos igual a 70\%. Apenas a amostra CAE-C apresentou resultados abaixo do limite sugerido, sendo que isto, juntamente com o resultado de equivalente de areia e desgaste cântabro, é um indicativo da baixa adesividade entre os agregados e o ligante asfáltico. O FN pode ser entendido como o número de ciclos no qual a taxa de deformação é mínima, ou seja, a declividade da curva de deformação permanente acumulada versus ciclos de carregamento é mínima [48]. O índice FN é a razão entre a deformação permanente acumulada no FN e o número de ciclos no FN. De acordo com WALUBITA et al. [49], misturas com menores valores de índice FN são mais estáveis e resistentes à deformação permanente.

Estudos indicam que as características dos agregados desempenham papel fundamental no comportamento quanto à deformação permanente. De acordo com AHLRICH [50], o método de dosagem e a granulometria são os principais fatores que controlam a deformação permanente. Já STAKSTON e BAHIA [51] consideram a angularidade dos agregados e a granulometria como sendo fatores principais na avaliação da deformação permanente. GOLALIPOUR et al. [52] afirmam que o bom desempenho de misturas asfálticas quanto a deformação permanente depende principalmente do bom intertravamento entre as partículas, logo, deve-se utilizar uma seleção granulométrica que permita a interação entre os diversos tamanhos de agregados.

Comparando as misturas de CAE com a mistura MCS quanto aos seus valores de FN e Índice FN, verifica-se que as amostras de CAE têm maiores valores de FN e menores Índices FN. As amostras CAE-A e CAE-B apresentam menores valores de porosidade FAD que a da mistura MCS, logo era esperado maiores valores de FN, mas isso não ocorreu. BASTOS et al. [53] apresentam critérios de FN para diferentes níveis de tráfego da literatura, conforme apresentado na Tabela 12. Analisando os valores de FN conforme sugerido por NASCIMENTO [10], considerando o valor de 300 ciclos para FN mínimo, a amostra CAE-C apresentou valores de FN extremamente altos, não se enquadrando para nenhuma das situações de tráfego propostas por NASCIMENTO [10]. As amostras CAE-A e CAE-B também não se enquadraram para nenhuma das situações de tráfego, tendo valores abaixo do sugerido pelo autor, indicando que estas misturas podem apresentar afundamento na trilha de roda precocemente. Logo, recomenda-se alteração na seleção dos materiais utilizados e no processo de dosagem dessas misturas.

Tabela 12: Critérios de FN para diferentes níveis de tráfego da literatura [53].

\begin{tabular}{|c|c|c|c|c|c|c|c|}
\hline \multirow{3}{*}{ PESQUISAS } & \multirow{3}{*}{$\mathrm{V}_{\mathrm{v}}(\%)$} & \multirow{3}{*}{$\begin{array}{c}\mathrm{T} \\
\left({ }^{\circ} \mathrm{C}\right)\end{array}$} & \multirow{3}{*}{$\begin{array}{c}\text { TENSÃO } \\
\text { (KPA) }\end{array}$} & \multicolumn{4}{|c|}{ NÍVEIS DE TRÁFEGO (NÚMERO N) } \\
\hline & & & & LEVE & MÉDIO & PESADO & $\begin{array}{c}\text { EXTREMAMENTE } \\
\text { PESADO }\end{array}$ \\
\hline & & & & $3 \times 10^{6}$ & $\begin{array}{l}3 \times 10^{6} \\
1 \times 10^{7}\end{array}$ & $\begin{array}{l}1 \times 10^{7} \\
3 \times 10^{7}\end{array}$ & $>3 \times 10^{7}$ \\
\hline Nascimento (2008) & 6,5 a 7,5 & 60,0 & 204 & - & 300 & 750 & - \\
\hline AAT (2011) & 4,7 a 8,2 & 31,3 a 54,3 & 600 & - & 53 & 190 & 740 \\
\hline Bonaquist (2012) & 6,0 a 7,3 & 49,6 & 600 & 15 & 50 & 135 & 415 \\
\hline Bastos et al. (2017) & 5,0 a 7,0 & 60,0 & 204 & - & 100 & 300 & $>1000$ \\
\hline
\end{tabular}

$\mathrm{V}_{\mathrm{v}}=$ Volume de vazios; $\mathrm{T}=$ Temperatura .

Os resultados de FN obtidos para as amostras CAE-C foram acima do esperado já que a porosidade FAD foi maior para a mistura CAE-C em relação à mistura MCS apresentada por BARROSO [12]. O comportamento da mistura CAE-C pode ser justificado pelo efeito que o envelhecimento do ligante causa no comportamento quanto à deformação permanente. De acordo com FERNÁNDEZ-GÓMEZ et al. [54], o en- 
velhecimento do ligante e o consequente aumento na rigidez da mistura faz com que sua resistência à deformação permanente aumente. Assim, verifica-se que a amostra CAE-C pode estar com o ligante asfáltico mais envelhecido que as demais e que isso também irá prejudicar o desempenho mecânico da mistura quando aplicada em uma obra real.

A elevada rigidez das misturas de CAE foi observada nas relações MR/RT, que apresentaram valores acima de 3000, e nos resultados de módulo dinâmico descritos a seguir. De acordo com LEITE et al. [55], a relação MR/RT pode ser um indicador da vida de fadiga do pavimento, visto que agrega parâmetros de rigidez e resistência. Os autores recomendam que as relações MR/RT sejam próximas de 3000 para que as misturas asfálticas tenham bom comportamento estrutural, ou seja, que as misturas sejam flexíveis e tenham boa resistência à tração; valores elevados indicam pior comportamento quanto à fadiga e misturas mais rigidas. De acordo com o estudo de FERNÁNDEZ-GÓMEZ et al. [54], misturas rígidas não possuem boa resistência ao trincamento por fadiga, o que ainda não pode ser confirmado para as amostras estudadas, pois o ensaio de fadiga não foi realizado nesta fase do estudo.

Os resultados de MD indicam as propriedades elásticas e viscoelásticas do CAE e estão apresentados nas Figuras 5 a 9. Analisando as curvas de módulo dinâmico da amostra CAE-C, percebe-se que a elevado valor de MD para as baixas e altas temperaturas quando comparada com a amostra CAE-B (Figura 5). Quando comparada com a mistura MCS, verifica-se que a amostra $\mathrm{CAE}-\mathrm{C}$ tem comportamento mais rígido apenas para as temperaturas de $37,8^{\circ} \mathrm{C}$ e $54,4^{\circ} \mathrm{C}$. As amostras CAE-A e CAE-B apresentam menores valores de módulo que a mistura MCS para baixas e altas temperaturas, sendo consideradas mais flexíveis.
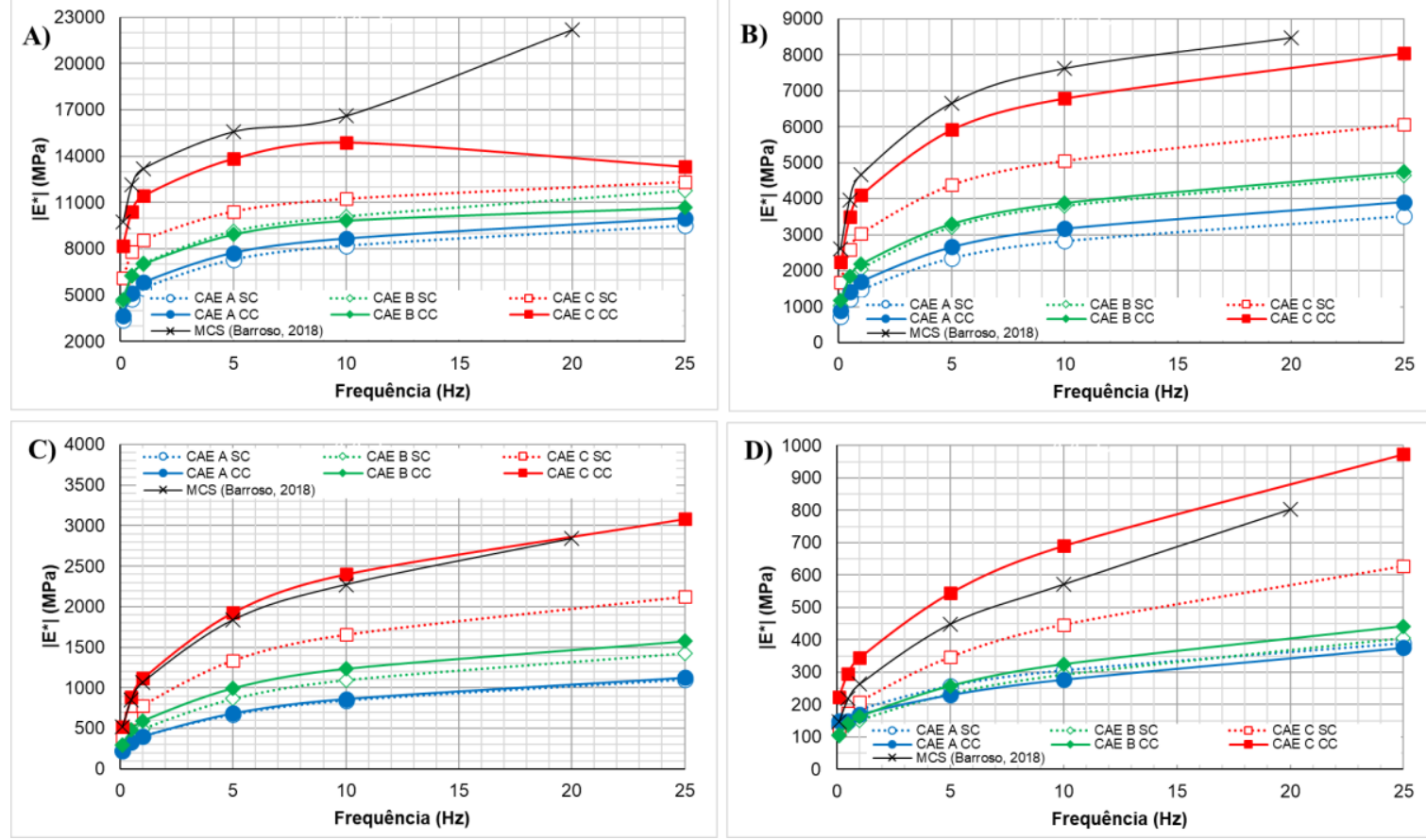

Figura 5: Módulo dinâmico para cada temperatura: A) $4,4^{\circ} \mathrm{C}$; B) $21,1^{\circ} \mathrm{C}$; C) $37,8^{\circ} \mathrm{C}$; D) $54,4^{\circ} \mathrm{C}$.

Observando-se os gráficos do ângulo de fase (Figura 6), a amostra CAE-A indicou comportamento mais viscoso sob baixa temperatura $\left(4,4^{\circ} \mathrm{C}\right)$, quando comparada com a mistura MCS. As misturas CAE-C apresentam menores valores de ângulo de fase para altas temperatura que as misturas MCS e CAE-B, indicando que esta tem comportamento menos viscoso com a passagem do tráfego. As amostras CAE-B apresentam valores de ângulo de fase maiores que os da amostra MCS, indicando que esta tem comportamento mais viscoso.

Observando-se os gráficos do ângulo de fase (Figura 6), a amostra CAE-A indicou comportamento mais viscoso sob baixa temperatura $\left(4,4^{\circ} \mathrm{C}\right)$, quando comparada com a mistura MCS. As misturas CAE-C apresentam menores valores de ângulo de fase para altas temperatura que as misturas MCS e CAE-B, indicando que esta tem comportamento menos viscoso com a passagem do tráfego. As amostras CAE-B apresentam valores de ângulo de fase maiores que os da amostra MCS, indicando que esta tem comportamento mais viscoso. 

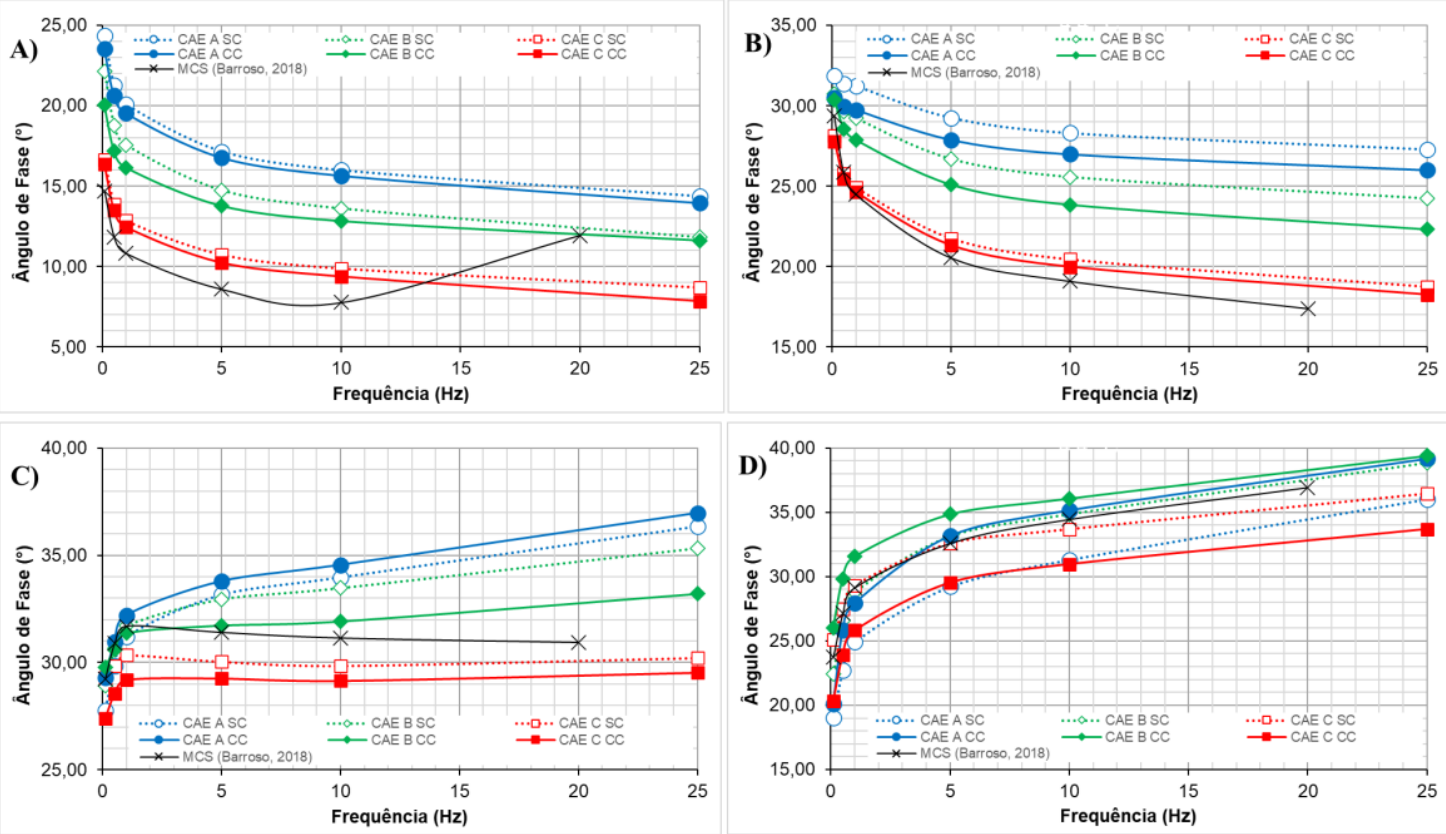

Figura 6: Ângulo de fase para cada temperatura: A) $4,4^{\circ} \mathrm{C}$; B) $21,1^{\circ} \mathrm{C}$; C) $37,8^{\circ} \mathrm{C}$; D) $54,4^{\circ} \mathrm{C}$.

O diagrama de Black (Figura 7) se dá pelo ângulo de fase $\delta$ versus o logaritmo do módulo complexo $\left|E^{*}\right|$, representando a relação entre a viscosidade e a rigidez da mistura. Além disso, o diagrama Black pode ser usado para avaliar a dispersão dos dados a partir do R-quadrado da linha de tendência. Os diagramas de Black, para as condições sem cura e com cura (Figura 7), indicam que as misturas de CAE, assim como a mistura MCS, têm um aumento do ângulo de fase até a temperatura de $37,8^{\circ} \mathrm{C}$ e uma posterior redução, sendo que há uma diminuição do valor do $\left|\mathrm{E}^{*}\right|$ com o aumento da temperatura. Para a condição sem cura, verifica-se que, quando comparadas com a mistura MCS, as misturas de CAE são menos rígidas e menos viscosas sob baixa temperatura $\left(4,4^{\circ} \mathrm{C}\right)$. Já para alta temperatura $\left(54,4^{\circ} \mathrm{C}\right)$ as misturas de $\mathrm{CAE}$ se mostraram com comportamento mais rígido e menos viscoso que a mistura MCS.
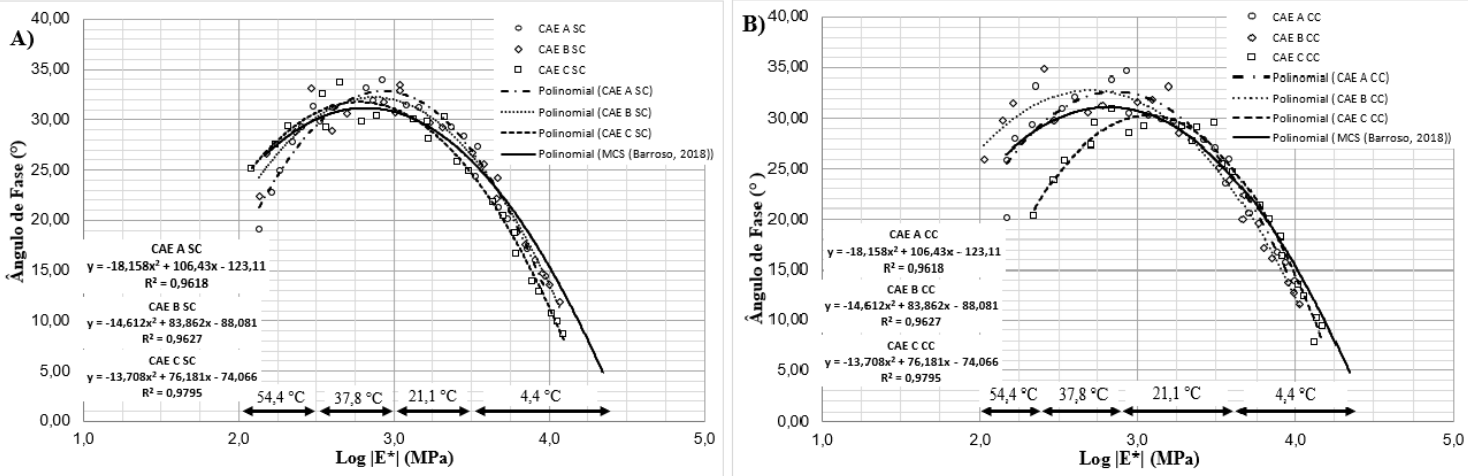

Figura 7: Diagrama de Black para as misturas de CAE: A) CAE SC; B) CAE CC.

Para a condição com cura, as misturas de CAE apresentam comportamento menos rígido e menos viscoso que a mistura MCS para baixa temperatura. Já para alta temperatura, a mistura CAE-B apresenta comportamento menos rígido e mais viscoso que a mistura MCS. Por outro lado, as misturas CAE-A e CAE-C apresentam comportamento mais rígido e menos viscoso que a mistura MCS O plano Cole-Cole (Figura 8) se dá pela relação entre os componentes reais $\left(\left|\mathrm{E}^{*}\right| \cdot \cos \delta\right)$ e imaginários $\left(\left|\mathrm{E}^{*}\right| \cdot \operatorname{sen} \delta\right)$ do módulo complexo. Com a parte real é possível analisar a componente elástica e recuperável da mistura. Já com a parte imaginária, tem-se o comportamento viscoso. O plano Cole-Cole para a condição sem cura ilustra que a amostra CAE-C tem os menores valores de $\left|\mathrm{E}^{*}\right|$.sen $\delta$ para baixa temperatura, indicando que seu retorno elástico é maior que 
os das amostras CAE-B e MCS, confirmando o comportamento menos viscoso observado no diagrama de Black. As misturas CAE-A e CAE-B também apresentam menores valores de $\left|E^{*}\right|$.sen $\delta$ para baixa temperatura quando comparadas com a mistura MCS. Já para a condição com cura, as amostras CAE-A e CAE-B mantêm seus componentes imaginários menores que os da amostra MCS; porém, a amostra CAE-C apresentou componente imaginário maior que a amostra MCS, indicando comportamento mais viscoso (Figura 8).

Com os resultados de MD foi possível plotar as curvas mestras das misturas de CAE para a temperatura de $21,1^{\circ} \mathrm{C}$ (Figura 9). As misturas de CAE apresentaram menores valores de módulos para baixas e altas frequências quando comparadas com a mistura MCS, sendo que apenas para frequências reduzidas abaixo de 0,0001 Hz a mistura CAE-C CC apresentou maiores valores de módulo. A análise da variação dos valores de $\log \alpha(T)$ permite avaliar a susceptibilidade do comportamento das misturas com a variação de temperatura, sendo que de acordo com a Tabela 13 as misturas de CAE apresentam menor susceptibilidade térmica quando comparadas com a mistura MCS, exceto para a mistura CAE-A CC.

Com o envelhecimento, as misturas asfálticas se tornam mais rígidas e mais viscosas, devido à oxidação dos componentes do ligante [47]. Logo, com a cura das misturas de CAE a céu aberto era esperado que estas apresentassem um comportamento mecânico mais rígido e mais viscoso. A Figura 10 compara o diagrama de Black para as misturas de CAE nas condições sem cura e com cura. É possível verificar que a mistura CAE-A apresenta pouca alteração em seu comportamento para baixa temperatura (menor que $21,1^{\circ} \mathrm{C}$ ); porém, para alta temperatura tem-se uma diminuição de rigidez e um aumento de sua viscosidade, caracterizada pelo maior ângulo de fase na condição com cura. A mistura CAE-B apresenta redução de sua rigidez e viscosidade para baixa temperatura e diminuição da rigidez e aumento da viscosidade para alta temperatura. Por fim, a mistura CAE-C apresenta aumento de sua rigidez e aumento da sua viscosidade para baixa temperatura e um aumento da rigidez e diminuição da viscosidade para alta temperatura.
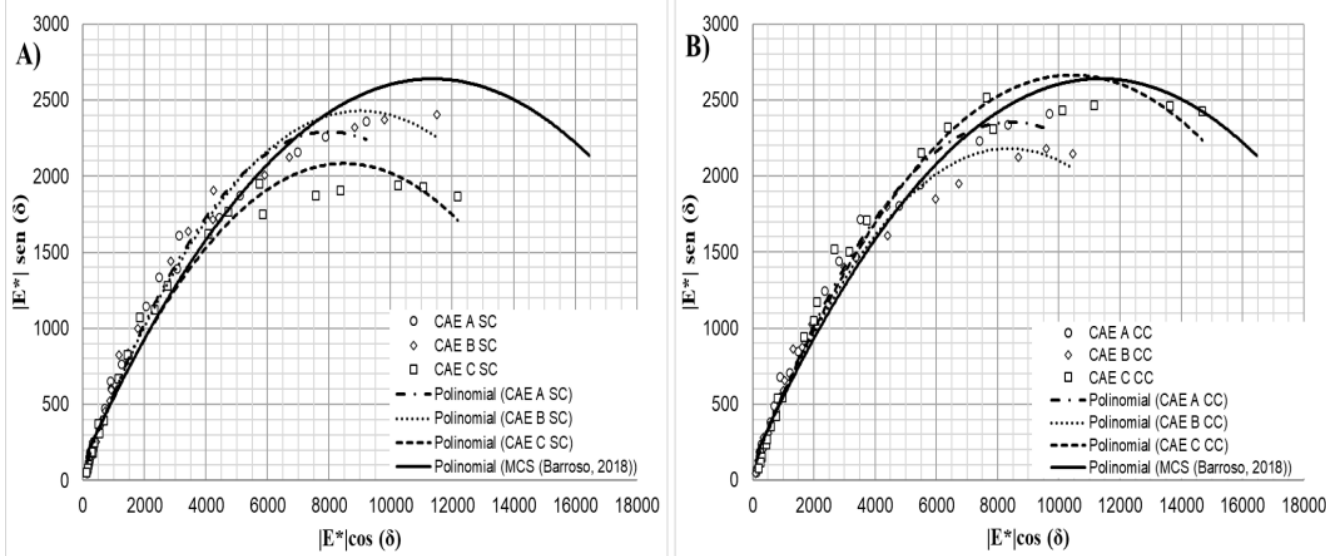

Figura 8: Plano Cole-Cole para as misturas de CAE: A) CAE SC; B) CAE CC.

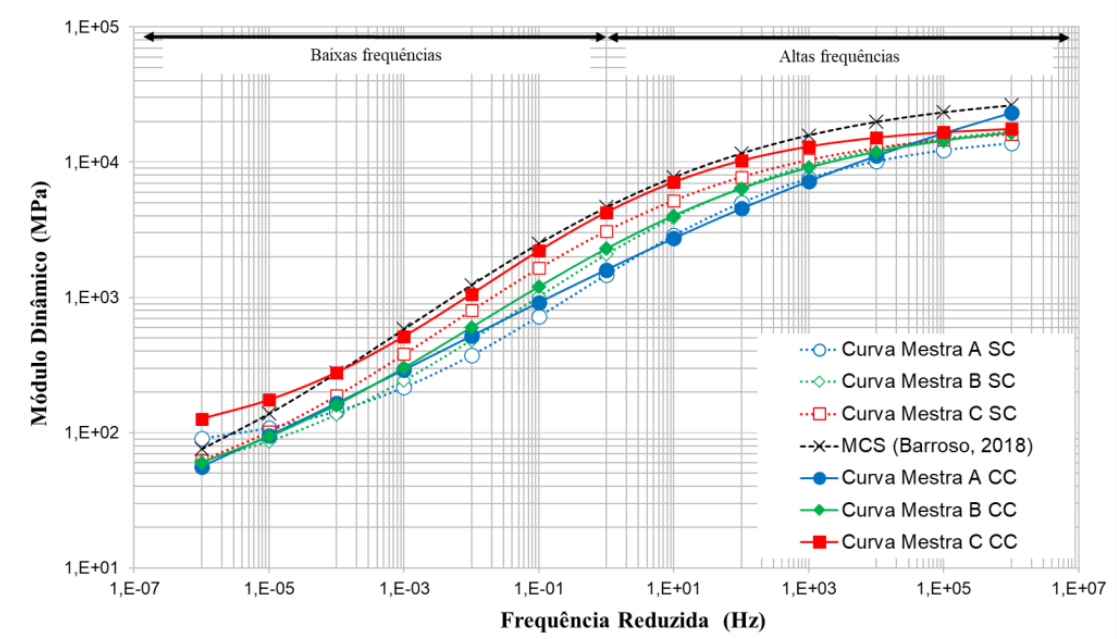

Figura 9: Curvas Mestras das misturas de CAE e MCS, para a temperatura de $21,1^{\circ} \mathrm{C}$. 
Tabela 13: Valores do $\log \alpha(T)$ para as misturas de CAE e MCS.

\begin{tabular}{c|c|c|c|c|c}
\hline \multirow{2}{*}{ MISTURAS } & \multicolumn{4}{|c|}{ TEMPERATURA $\left.\mathbf{(}^{\circ} \mathbf{C}\right)$} & \multirow{2}{*}{ VARIAÇÃo $\log \alpha(\mathbf{T})$} \\
\cline { 2 - 5 } & $\mathbf{4 , 4}$ & $\mathbf{2 1 , \mathbf { 1 }}$ & $\mathbf{3 7 , 8}$ & $\mathbf{5 4 , 4}$ & \\
\hline CAE-A SC & 2,213 & 0 & $-1,847$ & $-3,319$ & 5,532 \\
\hline CAE-A CC & 2,553 & 0 & $-2,160$ & $-3,917$ & 6,470 \\
\hline CAE-B SC & 2,203 & 0 & $-1,972$ & $-3,702$ & 5,905 \\
\hline CAE-B CC & 2,214 & 0 & $-2,033$ & $-3,876$ & 6,090 \\
\hline CAE-C SC & 2,313 & 0 & $-2,035$ & $-3,782$ & 6,095 \\
\hline CAE-C CC & 2,294 & 0 & $-1,953$ & $-3,556$ & 5,850 \\
\hline MCS [12] & 2,469 & 0 & $-2,158$ & $-3,997$ & 6,466 \\
\hline
\end{tabular}

Por fim, observou-se que nenhuma das misturas apresentou comportamento conforme o esperado. Em relação a resistência à tração, apenas a mistura CAE-B apresentou aumento no valor de RT, sendo um indicativo do aumento da rigidez desta mistura com a cura. Em relação ao MR, apenas a mistura CAE-A apresentou uma diminuição desse parâmetro, indicando que a mistura ficou menos resistente. A relação MR/RT aumentou para as três misturas, indicando aumento da rigidez das misturas. Além disso, os resultados de RTT indicam que houve um aumento da adesividade entre agregados e ligantes para as misturas de CAE. Por outro lado, houve um aumento do desgaste cântabro das amostras da CAE, indicando maior desagregação. O valor de FN aumentou apenas para a mistura CAE-B.

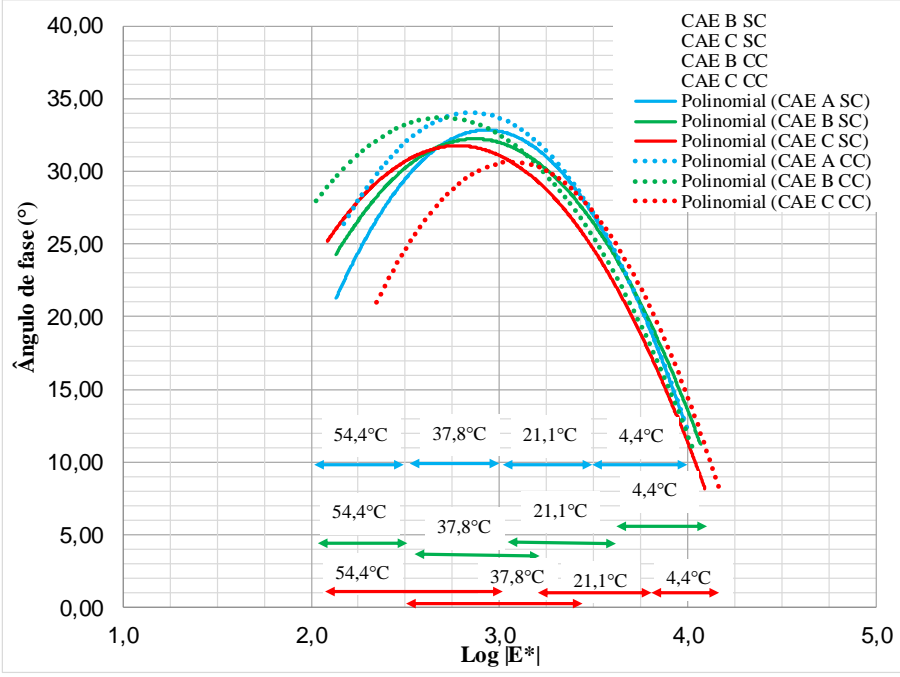

Figura 10: Diagrama de Black para as misturas de CAE nas condições SC e CC. A) CAE-A; B) CAE-B; C) CAE-C.

A análise do processo de cura do CAE tinha como objetivo tentar simular a densificação do CAE em campo. Com o processo de cura era esperada um aumento da rigidez misturas de CAE. Porém, os resultados foram inconclusivos, sendo que os valores de MD indicaram aumento da rigidez apenas para a mistura CAEC. Já os outros parâmetros indicaram aumento da rigidez apenas para a mistura CAE-B. Em estudos futuros recomenda-se que o processo de cura inclua a passagem de veículos para que os parâmetros mecânicos do CAE possam ser avaliados sob esse aspecto.

Os resultados obtidos indicam que as misturas CAE-B e CAE-C, provavelmente, são misturas ou que foram oxidadas durante a produção ou que ficaram estocadas por um longo período. Logo, torna-se inviável considerá-las na confecção de um revestimento asfáltico. Já a mistura CAE-A não apresentou características de uma mistura envelhecida. No entanto, considerando seus parâmetros volumétricos e mecânicos, a mistura CAE-A não é adequada para uso na camada de revestimento por apresentar alto volume de vazios quando compactada na temperatura de $60^{\circ} \mathrm{C}$ e baixos valores de RT e MR.

\section{CONCLUSÕES}

O estudo apresentado contribuiu para o conhecimento do CAE, sua composição e dosagem, sendo que a análise do CAE indicou que este não tem comportamento semelhante ao de um CA convencional, apresentando 
elevada variabilidade em seus parâmetros volumétricos e mecânicos.

A compactação por amassamento não foi capaz de densificar o CAE de forma suficiente para obter o volume de vazios de projeto, sendo que o parâmetro CDI indicou que as misturas de CAE apresentam baixa trabalhabilidade. A análise granulométrica indicou que as misturas de CAE não estão bem intertravadas. E que não são adequadas para uso como camada de revestimento na forma como os fabricantes sugerem, pois possui baixa trabalhabilidade e não atende aos parâmetros exigidos para normas de CA convencionais.

A análise comparativa entre os parâmetros físicos e mecânicos do CAE não se mostrou conclusiva, visto que o comportamento mecânico foi contrário ao indicado por seus parâmetros físicos. Além disso, verificou-se que o CAE pode envelhecer durante a estocagem, o que não é adequado. A realização dos ensaios mecânicos sem e com cura também se mostrou inconclusiva, visto que era esperado um aumento da rigidez das misturas com o processo de cura, o que não foi observado em todos os parâmetros mecânicos avaliados.

Por fim, verificou-se que a produção do CAE na região de Goiânia-GO ainda não é padronizada, apresentando materiais e composições diferentes, o que reforça a necessidade de uma especificação técnica para a definição de uma dosagem adequada, para o controle tecnológico durante a produção e a estocagem, bem como os parâmetros limites que devem ser atendidos para o uso desse material. Novos estudos são recomendados para avaliar o CAE nas condições após usinagem e estocado. Além disso, é recomendado o estudo do ligante utilizado na composição do CAE obtido diretamente com o fabricante, visando avaliar suas características e compará-las com ligantes convencionais utilizados em concretos asfálticos convencionais da região.

\section{AGRADECIMENTOS}

Os autores agradecem à Agência Goiana de Infraestrutura e Transportes (GOINFRA) pela parceria no projeto e o apoio da Coordenação de Aperfeiçoamento de Pessoal de Nível Superior - Brasil (CAPES) - Código de Financiamento 001 à CAPES pelas bolsas concedidas.

\section{BIBLIOGRAFIA}

[1] BERNUCCI, L.B., MOTTA, L.M.G.,CERATTI, et al., Pavimentação asfáltica: Formação básica para engenheiros, 1 ed., Rio de Janeiro, Petrobras, 2006.

[2] SEFIDMAZGI, N.R., BAHIA, H.U., "Effect of compaction conditions on aggregate packing using 2dimensional image analysis and the relation to performance of HMA", Materials and Structures/Materiaux et Constructions, v. 47, pp. 1313-1324, 2014.

[3] ARAGÃO, F.T.S., PAZOS, A.R.G., MOTTA, et al.,"Effects of morphological characteristics of aggregate particles on the mechanical behavior of bituminous paving mixtures", Construction and Building Materials, v. 123, pp. 444-453, 2016.

[4] ARCHILLA, A., DIAZ, L., "Effects of Asphalt Mixture Properties on Permanent Deformation Response", Transportation Research Record: Journal of the Transportation Research Board, v. 2210, pp. 1-8, 2011.

[5] KIM, S., ROQUE, R., BIRGISSON, B., et al.,"Porosity of the Dominant Aggregate Size Range to Evaluate Coarse Aggregate Structure of Asphalt Mixtures", Journal of Materials in Civil Engineering, v. 21, pp. 32-39, 2009.

[6] FERREIRA, J.L.S., SOARES, J.B., BASTOS, J.B.S., "Métodos de seleção granulométrica com foco na resistência à deformação permanente", Transportes, v. 24, pp. 46, 2016.

[7] VAVRIK, W.R., HUBER, G., PINE, W.J., et al.,"Bailey Method for Gradation Selection in Hot-Mix Asphalt Mixture Design.", Transportation Research CIRCULAR, v. E-C044, pp. 34, 2002.

[8] MENDES, L.D.O., MARQUES, G.L.O., "Avaliação da influência do método Bailey no processo de dosagem e desempenho de misturas asfálticas", Transportes, v. 20, pp. 35-43, 2013.

[9] MAHMOUD, A.F.F., BAHIA, H.U., "Using the Gyratory Compactor to Measure Mechanical Stability of Asphalt Mixtures", Wisconsin High Research Program, 2004.

[10] NASCIMENTO, L.A.H., Nova abordagem da dosagem de misturas asfálticas densas com uso do compactador giratório e foco na deformação permanente, Dissertação de M.Sc., COPPE/ UFRJ, Rio de Janeiro, RJ, Brasil, 2008.

[11] LEIVA, F.,WEST, R.C., "Analysis of Hot-Mix Asphalt Lab Compactability Using Lab Compaction Parameters and Mix Characteristics", Transportation Research Record: Journal of the Transportation Research Board, v. 2057, pp. 89-98, 2008. 
[12] BARROSO, L.X., Avaliação da Dosagem e do Comportamento Mecânico de Concretos Asfálticos produzidos em Goiás, Dissertação de M.Sc., PPGECON/UFG, Goiânia, GO, Brasil, 2018.

[13] ORESCOVIK, M., PIRES, G.M., BRESSI, S. et al.,"Quantitative assessment of the parameters linked to the blending between reclaimed asphalt binder and recycling agent: A literature review. "Construction and Building Materials, v. 234, p. 117323, 2020.

[14] SANTANA, A.C.S.T., LOURENÇO, V.M. Q., "Análise das propriedades físicas e mecânicas de mistura asfáltica usinada à quente ensacada para aplicação à frio", In: Proceedings of the XXXI Congresso Nacional de Pesquisa em Transporte da ANPET, pp. 1438-1449, Recife.

[15] DNIT - DEPARTAMENTO NACIONAL DE INFRAESTRUTURA DE TRANSPORTES, "DNIT 031ES: Pavimentos flexíveis - Concreto asfáltico", Rio de Janeiro, Brasil, p. 14.

[16] OLIVEIRA, A.G.B., "Estudos Preliminares de Mistura Asfáltica do tipo CBUQ Estocável para uso em Pavimentação no Estado de Goiás", Monografia, Escola de Engenharia Civil/UFG, Goiânia, GO, Brasil, 2017.

[17] MEJÍAS-SANTIAGO, M.,VALLE-ROLDÁN, F., PRIDDY, L.P., Certification Tests on Cold Patch Asphalt Repair Materials for Use in Airfield Pavements Geotechnical and Structures Laboratory Certification Tests on Cold Patch Asphalt Repair Materials for Use in Airfield Pavements; Vicksburg;

[18] ASTM - AMERICAN SOCIETY FOR TESTING AND MATERIALS, "D2041: Standard Test Method for Theoretical Maximum Specific Gravity and Density of Bituminous Paving Mixtures", EUA, p. 5.

[19] DNER - DEPARTAMENTO NACIONAL DE ESTRADAS DE RODAGEM, "DNER 083 - ME: Agregados - Análise granulométrica", Rio de Janeiro, Brasil, pp. 3-7.

[20] DNER - DEPARTAMENTO NACIONAL DE ESTRADAS DE RODAGEM, “DNER 053 - ME: Misturas Betuminosas - Percentagem de Betume", Rio de Janeiro, Brasil.

[21] DNER - DEPARTAMENTO NACIONAL DE ESTRADAS DE RODAGEM, "DNER 085 - ME: Material finamente pulverizado - determinação da massa específica real Rio de Janeiro, Brasil, p. 3.

[22] DNER - DEPARTAMENTO NACIONAL DE ESTRADAS DE RODAGEM, "DNER 084 ME: Agregado miúdo - determinação de densidade real", Rio de Janeiro, Brasil, p. 3.

[23] ASTM - AMERICAN SOCIETY FOR TESTING AND MATERIALS, "Standard Test Method for Relative Density ( Specific Gravity ) and Absorption of Fine Aggregate", pp. 1-6.

[24] DNIT - DEPARTAMENTO NACIONAL DE INFRAESTRUTURA DE TRANSPORTES, "DNER-ME 081: Agregados - determinação da absorção e da densidade de agregado graúdo.", Rio de Janeiro, Brasil, pp. 01-06.

[25] DNER - DEPARTAMENTO NACIONAL DE ESTRADAS DE RODAGEM, "DNER 054 ME:Equivalente de areia", Rio de Janeiro, Brasil , p. 10.

[26] DNER - DEPARTAMENTO NACIONAL DE ESTRADAS DE RODAGEM, "DNER 086 - ME: Agregado - Determinação do Índice de Forma", Rio de Janeiro, Brasil, p. 5.

[27] DNER - DEPARTAMENTO NACIONAL DE ESTRADAS DE RODAGEM, "Agregados determinação do índice de degradação de rochas após compactação Marshall, com ligante - IDml e sem ligante - IDm", Rio de Janeiro, Brasil, pp. 1-7.

[28] ABNT - AsSOCIAÇÃo BRASILEIRA DE NORMAS TÉCNICAS, "NBR 15184 - Materiais betuminosos Determinação da viscosidade em temperaturas elevadas usando um viscosímetro rotacional", p. 4.

[29] ABNT- ASSOCIAÇÃo BRASILEIRA DE NORMAS TÉCNICAS, "NBR 6560 - Ligantes asfálticos Determinação do ponto de amolecimento - Método do anel e bola", p. 7.

[30] ABNT - ASSOCIAÇ̃̃o BRASILEIRA DE NORMAS TÉCNICAS, "NBR 6576 - Materiais asfálticos Determinação da penetração", p. 7.

[31] ABNT- ASSOCIAÇão BRASILEIRA DE NORMAS TÉCNICAS, "NBR 6296 - Produtos betuminosos semissólidos - Determinação da massa específica e densidade relativa", p. 6.

[32] ABNT - ASSOCIAÇÃo BRASILEIRA DE NORMAS TÉCNICAS, "NBR 15087 - Misturas asfálticas Determinação da resistência à tração por compressão diametral", p. 5.

[33] ABNT - ASSOCIAÇÃo BRASILEIRA DE NORMAS TÉCNICAS, "NBR 16018 - Misturas asfálticas Determinação da rigidez por compressão diametral sob carga repetida", p. 12. 
[34] DNER - DEPARTAMENTO NACIONAL DE ESTRADAS DE RODAGEM, "DNER 383 - ME: Desgaste por abrasão de misturas betuminosas com asfalto polímero - ensaio Cantabro", Rio de Janeiro, Brasil, p. 2.

[35] ABNT - AsSOCIAÇão BRASILEIRA DE NORMAS TÉCNICAS, "NBR 15617 - Misturas asfálticas Determinação do dano por umidade induzida", p. 5.

[36] AASHTO - AMERICAN ASSOCiaTion of State Highway AND TRANSPORTATION OfFicials, "T 378 Standard Method of Test for Determining the Dynamic Modulus and Flow Number for Asphalt Mixtures Using the Asphalt Mixture Performance Tester (AMPT)", p. 21.

[37] REZENDE, D.A.T., Caracterização amostral de Concreto Asfáltico Estocável por meio de ensaios laboratoriais, Monografia, Escola de Engenharia Civil/ UFG, Goiânia, GO, 2019.

[38] ASTM - AMERICAN SOCIETY FOR TESTING AND MATERIALS, "D5404 - Standard practice for recovery of asphalt from solution using the rotary evaporator", p. 3.

[39] GOUVEIA, L., Contribuiç̃oses ao estudo da influência de propriedades de agregados no comportamento de misturas asfálticas densas, Tese de D. Sc., Escola de Engenharia de São Carlos/USP, São Carlos, SP, 2006.

[40] DNIT - DePartamento NACIONAL DE INFRAESTRUTURA DE TRANSPORTES, "Cimentos asfálticos de petróleo - Especificação de material", Rio de Janeiro, Brasil, p. 06.

[41] BARROSO, L., REZENDE, L., FARIAS, M., "Study of the relationship between the aggregates gradation, binder properties and densification indexes for an asphalt concrete rutting resistance", In: Proceedings of the CETRA - 5th International Conference on Road and Rail Infrastructure, pp 445-452, Zadar, Croácia, Maio 2018.

[42] AASHTO- AMERicAN ASSOCiation OF STATE Highway AND TRANSPORTATION OFFICIALS, "M 323 Standard Specification for Superpave Volumetric Mix Design", p. 17.

[43] GREENE, J., CHUN, S., CHOUBANE, B., "Enhanced Gradation Guidelines to Improve Asphalt Mixture Performance", Transportation Research Record: Journal of the Transportation Research Board, v. 2456, pp. 3-10, 2015.

[44] PROWELL, B.D., BROWN, E.R., Superpave Mix Design: Verifying Gyration Levels in the Ndesign Table, Washington, The National Academies Press, 2007.

[45] SOUSA, J.B., CRAUS, J., MONISMITH, C.L., Summary Report on Permanent Deformation in Asphalt Concrete, Washington, Strategic Highway Research Program, 1991.

[46] NOGUEIRA, M.L., Avaliação do controle de qualidade de misturas asfálticas e análise do reflexo do nível de qualidade no desempenho dos revestiemntos asfálticos, Dissertação de M. Sc., Programa de Pósgraduação em Engenharia Civil, Porto Alegre, RS, 2011.

[47] JUNG, S.H., The Effects of Asphalt Binder Oxidation on Hot Mix Asphalt Concrete Mixture Rheology and Fatigue Performance, Dissertação de PhD, Texas A\&M University, 2006.

[48] ASTM - AMERICAN SOCIETY FOR TESTING AND MATERIALS, "D 4867 - Standard Test Method for Effect of Moisture on Asphalt Concrete Paving Mixtures", p. 5.

[49] WALUBITA, L.F., ZHANG, J., ALVAREZ, et al., "Exploring the flow number (FN) index as a means to characterise the HMA permanent deformation response under FN testing", Journal of the South African Institution of Civil Engineering, v. 55, pp. 103-112, 2013.

[50] AHLRICH, R., "Influence of Aggregate Properties on Performance of Heavy-Duty Hot-Mix Asphalt Pavements", Transportation Research Record: Journal of the Transportation Research Board, v. 1547, pp. 7-14, 1996.

[51] STAKSTON, A.D., BAHIA, H.U., The effect of fine aggregate angularity, asphalt content and performance graded asphalts on hot mix asphalt performance, Department of Civil and Environmental Engineering, University of Wisconsin-Madison, 2003.

[52] GOLALIPOUR, A., JAMSHIDI, E., NIAZI, Y., et al.,"Effect of Aggregate Gradation on Rutting of Asphalt Pavements", Procedia - Social and Behavioral Sciences, v. 53, pp. 440-449, 2012.

[53] BASTOS, J.B. S., SOARES, J.B., NASCIMENTO, L.A.H., "Critérios para os resultados do ensaio uniaxial de carga repetida de misturas asfálticas em laboratório a partir do desempenho em campo", Transportes, v. 25, pp. 19, 2017.

[54] FERNÁNDEZ-GÓMEZ, W.D., VIDES-BERDUGO, A.C., RONCALLO-CONTRERAS, S.P., et al., "Effects of environmental aging and ultra violet radiation on asphalt mixture dynamic modulus, 
permanent deformation and fatigue life", Revista Facultad de Ingeniería Universidad de Antioquia, pp. 89-96, 2016.

[55] LEITE, L.F.M., MOTTA, L.M.G., BERNUCCI, L.L.B., et al., "Mechanical behavior of asphalt rubber mixes prepared in laboratory", In: Proceedings of the Asphalt Rubber the Pavement Material of the 21 Century, pp. 309-318, Braga, 2000.

\section{ORCID}

Isabela Silva de Carvalho

https://orcid.org/0000-0002-4820-3734

Lilian Ribeiro Rezende

https://orcid.org/0000-0002-6755-8282

João Paulo Souza Silva

https://orcid.org/0000-0003-3297-8276

Douglas Andrez Tavares Rezende

https://orcid.org/0000-0002-9640-5250 